\title{
Correction of artificial jumps in the historical geomagnetic measurements of Coimbra Observatory, Portugal
}

\author{
A. L. Morozova ${ }^{1}$, P. Ribeiro ${ }^{1,2}$, and M. A. Pais ${ }^{1,3}$ \\ ${ }^{1}$ Centre for Geophysics of the University of Coimbra, University of Coimbra, Coimbra, Portugal \\ ${ }^{2}$ Geophysical and Astronomical Observatory of the University of Coimbra, Coimbra, Portugal \\ ${ }^{3}$ Physics Department, University of Coimbra, Coimbra, Portugal
}

Correspondence to: A. L. Morozova (anna_m@teor.fis.uc.pt)

Received: 7 October 2013 - Revised: 2 December 2013 - Accepted: 6 December 2013 - Published: 27 January 2014

\begin{abstract}
The Coimbra Magnetic Observatory (International Association of Geomagnetism and Aeronomy code COI) in Portugal has a long history of observation of the geomagnetic field, spanning almost $150 \mathrm{yr}$ since the first geomagnetic measurements in 1866 . These long instrumental geomagnetic records provide very important information about variability of geomagnetic elements and indices, their trends and cycles, and can be used to improve our knowledge on the sources that drive variations of the geomagnetic field: liquid core dynamics (internal) and solar forcing (external).

However, during the long life of the Coimbra Observatory, some inevitable changes in station location, instrument's park and electromagnetic environment have taken place. These changes affected the quality of the data collected at COI causing breaks and jumps in the series of geomagnetic field components and local $\mathrm{K}$ index. Clearly, these inhomogeneities, typically shift-like (step-like) or trend-like, have to be corrected or, at least, minimized in order for the data to be used in scientific studies or to be submitted to international databases.

In this study, the series of local $\mathrm{K}$ index and declination of the geomagnetic field are analysed: the former because it allows direct application of standard homogenization methods and the latter because it is the longest continuous series produced at COI. For the homogenization, visual and statistical tests (e.g. standard normal homogeneity test) have been applied directly to the local geomagnetic $\mathrm{K}$ index series (from 1951 to 2012). The homogenization of the monthly averages of declination (from 1867 to 2012) has been done using visual analysis and statistical tests applied to the time series of the first differences of declination values, as an approximation to the first time derivative. This allowed not only
\end{abstract}

estimating the level of inhomogeneity of the studied series but also detecting the highly probable homogeneity break points. These points have been cross-checked with the metadata, and the COI series have been compared with reference series from the nearest geomagnetic stations and, in the case of declination series, from the recent geomagnetic field model COV-OBS to set up the required correction factors. As a result, the homogenized series measured in COI are considered to be essentially free of artificial shifts starting from the second half of the 20th century, and ready to be used by the scientific community.

Keywords. Geomagnetism and paleomagnetism (time variations, secular and long term; instruments and technique)

\section{Introduction}

Historical instrumental records provide valuable information about the variability of different geophysical parameters, their trends and periodicities. This information is significant both to study past variations and to predict future ones. There is a variety of possible uses for geomagnetic observations, from practical applications related to geophysical prospection, directional drilling, aviation, prediction of space weather events, to more fundamental research related to the Earth's core dynamics. Monthly and annual means of observatory measurements are, in fact, used for modelling the geomagnetic secular variation (first time derivative of the geomagnetic field, SV - secular variation), which is believed to be generated by fluid flows at the top of the earth's core (e.g. Jackson and Finlay, 2007). Great importance was attached to sudden changes of the geomagnetic field derivative, called 
geomagnetic jerks, that were identified in the time series of geomagnetic observatories (e.g. Mandea et al., 2010), whose occurrence has been impeding a more efficient prediction at decadal timescale (Maus et al., 2008; Beggan and Whaler, 2010).

For more than $10 \mathrm{yr}$ now, several satellite missions have taken place with scalar and vector magnetometers on board low-Earth-orbiting satellites. Satellite data have brought a new impetus for geomagnetic field modelling, due to high accuracy and to high global spatial and temporal resolutions. But observatory ground data continue to be essential, because they properly separate local time variations from advective variations, are outside of electrical current source regions and provide the continuity of time series (e.g. Olsen et al., 2010). This last point cannot be overstated, in a period when, due to the end of CHAMP satellite mission in September 2010 (http://op.gfz-potsdam.de/champ/) and SWARM satellite constellation launch in November 2013, the geomagnetism community now faces a $3 \mathrm{yr}$ gap in vector satellite data.

The present global network of magnetic observatories is not only of main importance to complement and sometimes compensate for the lack of satellite data. In the case of historical observatories, they provide a very long continuous series of more than $150 \mathrm{yr}$ and are of great importance for the longterm geomagnetic field models. The same motivation led Korte et al. (2009) to carry out the compilation of a large number of direct and indirect historical measurements of declination for southern Germany and surrounding areas, in order to improve historical geomagnetic field models for this region. In our study, we assess directly the influence of Coimbra data in the COV-OBS geomagnetic field model recently computed by Gillet et al. (2013) using global observatory data since 1840 together with satellite records since 1999 to cover continuously the whole 1840-2010 time period. The employment of Coimbra Magnetic Observatory (COI) data changes significantly the model prediction for Coimbra region during the 19th century (see Sect. 5).

The longest time series from historical observatories can also provide information on geomagnetic indices that are proxies of the solar activity for periods when accurate observations of the Sun surface were still lacking. For instance, Svalgaard and Cliver (2010) introduced a new index, IDV, which correlates with the strength of the interplanetary magnetic field (IMF). As this index is computed from hourly mean values of the horizontal component $H$ measured at magnetic observatories, they could reconstruct the IMF backwards in time until 1835. As for Vokhmyanin and Ponyavin (2013), they reconstructed the IMF polarities until 1844 from the difference between the mean diurnal curve and the daily variation of the $H(D)$ component at the observatories of Helsinki and Saint Petersburg.

Unfortunately, most of long-term series contain inhomogeneities or homogeneity breaks (hereafter "breaks" or "HBs") caused by a number of non-natural sources that can cause trends, shifts and jumps. The origin of such breaks could be related to changes in instruments, instrument positions, measurement procedures and calculation methods and similar. Such HBs, which we call "artificial", without a doubt, have to be identified, listed in metadata and, if possible, corrected before data series may be used in scientific studies. The task of detection and correction of the artificial homogeneity breaks is complicated by the fact that not all detected breaks are of non-natural origin. Statistical tests often used to find the homogeneity breaks are constructed in a way that they detect a change of the baseline or running mean of a series. They cannot distinguish natural trends from artificial ones; besides, they could, for instance, pick the natural periodicities as a sequence of growing and declining trends. Therefore, the artificial HBs have to be separated from others, and this task can be done using the metadata - a record of the station history, instrument replacements and repairs, changes of the measurement and calculation methods, relocation, environmental changes that could affect measured data, etc.

In this paper we perform the homogeneity analysis of two long-term series of geomagnetic parameters measured in the Coimbra Magnetic Observatory: a series of monthly means of declination $(D)$ of the geomagnetic field for the period from July 1867 to October 2012 (07/1867-10/2012), and a series of monthly means of daily sums of the local geomagnetic K index (Ki) for the period from October 1951 to December 2012 (10/1951-12/2012) - see Sect. 2.2 for the description of the $\mathrm{K}$ index. We then suggest corrections for the artificial HBs found.

Section 2 gives an account of the history of the COI observatory and of the different instruments and routines that have been in use; Sect. 3 explains the main procedures of homogenization tests; Sects. 4 and 5 give a detailed account of the procedures applied to the Ki and to the $D$ series, respectively; finally, Sect. 6 draws the main conclusions.

\section{The magnetic observatory of Coimbra - history and metadata}

The Magnetic Observatory of Coimbra (International Association of Geomagnetism and Aeronomy code COI) is presently run by the Geophysical and Astronomical Observatory of the University of Coimbra and has been in operation for almost $150 \mathrm{yr}$. During its long history two main periods can be recognized on the basis of two different operating sites: the first period extends from the observatory's foundation in 1864 to its relocation in 1932 and refers to the Cumeada site $\left(40^{\circ} 12.4^{\prime} \mathrm{N}, 8^{\circ} 25.4^{\prime} \mathrm{W} ; 140 \mathrm{~m}\right.$ a.s.l. $)$; the second period extends from 1932 to the present and refers to the second site Alto da Baleia $\left(40^{\circ} 13^{\prime} \mathrm{N}, 8^{\circ} 25.3^{\prime} \mathrm{W} ; 99 \mathrm{~m}\right.$ a.s.l.). Nonetheless, and as presented below, other shorter periods can be noticed because of instrumental and/or operational changes. 


\subsection{Site of Cumeada}

Although the first magnetic measurements date from 1864, the observatory's regular functioning started two years later (June 1866) with the absolute observations of inclination $(I)$ and horizontal field $(H)$. These were complemented with the absolute values of declination $(D)$ in July 1867 . The first instrumentation set included as absolute instruments a Gibson (no. 4) unifilar magnetometer ( $H$ and $D$ measurements) and an inclinometer of Barrow (no. 37) ( $I$ measurements). For the continuous recording of magnetic variations of $H, D$ and $Z$ (vertical) components, a set of Adie variographs (Kew pattern) was also installed in July 1867. All these first instruments were brought from England after calibration in the Kew Observatory by Jacinto de Sousa, the first director of the Meteorological and Magnetic Observatory of the University of Coimbra (Seiça e Santos, 1995).

Concerning the absolute instruments and observational routines, the first inclinometer of Barrow (used since June 1866) was replaced in September 1876 by a John Dover (no. 31) inclinometer, which ended up being used in the absolute measuring of $I$ until 1935 (see below). The unifilar magnetometer of Gibson, used in the first observations of $H$ and $D$, was replaced in January 1878 by the Elliott \& Bros. (no. 40) magnetometer, which was used for more than 75 yr. During the first operational period in Cumeada (18661932), the absolute measurements of $H$ and $I$ were done approximately three times per month. However, the declination, which until July 1877 used also to be measured three times per month, started on this date to be measured on a bidaily schedule (at 08:00 and 14:00 LT); the difference of declination values at 08:00 and 14:00 gives an approximate value for the amplitude of diurnal variation, and the monthly mean of diurnal variation started being published in this way together with the ordinary monthly means of declination (Ferraz de Carvalho, 1920).

Yet regarding the absolute measurement of $D$, an utmost methodological change occurred in July 1875 that resulted in a clear improvement of data series. Until this date, the geographical meridian was determined by the hour angle, noting the times of the passages of the sun through the telescope reticule. However, this procedure was changed with the installation of an azimuthal mark approximately $1 \mathrm{~km}$ away from the observatory, allowing for greater ease and accuracy in the process of determining the geographical meridian.

Concerning the continuous recording, the Adie variographs started running in 1867 and worked more or less irregularly (with the main problems occurring in the vertical component) until September 1883. The variographs were then disassembled due to construction work and installation of facilities (Seiça e Santos, 1995). After their reinstallation, in September 1885, an almost complete set of daily magnetograms (recorded on photosensitive paper with a normal running speed of $15.2 \mathrm{~mm} \mathrm{~h}^{-1}$ ) was obtained until October 1914. By this time, it was recognized that the magnetic field induced by electrical currents circulating in the tram railways (which started being installed in Coimbra since 1911) was significant and superposed to the natural field, disturbing especially the variograph of $Z$, which was finally stopped in November 1914 (Ferraz de Carvalho, 1920). The horizontal $(H, D)$ variographs were kept in use until March 1933, despite the strong perturbations caused by the installation in 1929 of a new tram line only $50 \mathrm{~m}$ away from the variograph house. These changes ultimately dictated the re-location of the magnetic observatory.

In spite of the long series of magnetograms obtained with the Adie variographs (1867-1932), their reduction (i.e. the calculation of hourly means) only started in January 1919 (Ferraz de Carvalho, 1920). Before this year all published monthly values are based uniquely on the absolute measurements of $H, D$ and $I$ components.

\subsection{Site of Alto da Baleia}

To overcome the electromagnetic perturbations due to the tram lines, a new site was selected approximately $2.5 \mathrm{~km}$ north of the first location, Alto da Baleia. This relocation sets the beginning of the second operational period, with magnetic observations being resumed in 1932 at the new site.

To re-equip the new observatory for the continuous recording of magnetic variations, a set of Eschenhagen variographs made by the Askania house was acquired. Mainly due to incorrect installation of the new variographs, but also due to lack of photographic paper and oil during the Second World War, the continuous recordings were perturbed during the first $10 \mathrm{yr}$ and discontinued at the end of 1941.

Regarding the absolute measurements, the oversimplification of observation routines and the non-negligible perturbations mainly related to the aging and drift of instruments are responsible for apparent low quality of the geomagnetic series during the first $20 \mathrm{yr}$ in Alto da Baleia. In addition, the regular measurements of $I$ (which used to be made with a John Dover (no. 31) inclinometer until October 1935 and with a Sartorius earth inductor (no. 2854) afterwards) were discontinued in 1939. On the contrary, the $D$ and $H$ absolute observations were made on a regular basis with the magnetometer of Elliott \& Bros. until the end of 1948. However, the published annual/monthly means of $H$ and $D$ for the years 1949 and 1950 were obtained by linear interpolation (Custódio de Morais, 1952).

In 1951, Custódio de Morais, the new director of the Geophysical Institute, was responsible for the re-installation of the Eschenhagen variographs, and the continuous recording of $H, D$, and $Z$ components began properly in October of that year. These classic variographs were kept in use for more than 50 yr until August 2006.

Together with the variograph re-installation, the construction of a new absolute house in 1951 set a new stage in the observatory history. Nonetheless, during 1951 the absolute measurements of $H, D$ and $I$ were still obtained with the 
same old set of instruments (the unifilar magnetometer of Elliott \& Bros. for $H$ and $D$, and the Sartorius earth inductor for $I$ ). In the beginning of 1952, the absolute measurement of $I$ was abandoned and the measurement of $Z$ was adopted instead. Since this year, the measurements of $H$ and $Z$ have been respectively obtained with a quartz horizontal magnetometer (QHM) and a balance magnetometer zero (BMZ). In 1955 the old Elliott magnetometer used to measure absolute $D$ values was finally replaced by an Askania Werke AG magnetic theodolite (declinometer). Together with the Eschenhagen variographs, these new absolute instruments (QHM, BMZ and Askania declinometer) were kept in use until 2006.

In relation to the quality of data, this long period (19522006) can be separated into two distinct parts (Pais and Miranda, 1995):

1. from 1952 to 1987: the quality of geomagnetic series is comparable to what was obtained in most observatories of that epoch, allowing, for instance, the local identification and quantification of the global jerks of 1969 and 1978;

2. from 1987 to 2006: the Coimbra data began showing some non-negligible artificial perturbations mainly related to the aging and drift of instruments, technical difficulties in performing certain types of observations, as well as with the increasing urban magnetic noise. In particular, the construction of a neighbourhood house occurred during 1989-1991 only 15 and $30 \mathrm{~m}$ away from the absolute and variation houses, respectively.

In 2006 the Geophysical Institute of the University of Coimbra was finally able to replace completely the set of old instruments with modern ones. The Askania declinometer was the first to be replaced, and in January 2006 the declination started to be measured by a DI-flux magnetometer (consisting of a fluxgate sensor MAG-01H mounted on MG2KP steel-free theodolite). This change of instruments was accompanied by the selection of a new azimuthal mark and new reference pillar (no. 4 in the absolute house). The QHM and the BMZ were discontinued in June 2006, and the base lines of $H$ and $Z$ started to be determined by means of absolute values of $D, I$ (using the DI-flux magnetometer ) and $\mathrm{F}$ (Geometrics G-856 proton magnetometer). In September 2006 the Eschenhagen variographs were replaced by the modern digital variometer FGE (version J; DMI), which was installed to record the variations of the same geomagnetic components (HDZ) with sampling rate of $1 \mathrm{~Hz}$. Finally, in June 2007, the continuous recording of absolute values of $F$ started, using a new proton magnetometer (the Overhauser GSM90-F1, Geometrics). All these changes resulted clearly in an increase in baseline stability and in an evident quality improvement of obtained data series (showing a reduced noise level).
Starting from October 1951 the good quality of magnetograms obtained with the re-installed Eschenhagen variographs allowed the calculation of the local $\mathrm{K}$ index, which is based on the variation range of the horizontal components $(H, D)$ with respect to the regular daily variation. The $\mathrm{K}$ index values, available since October 1951, were hand-scaled during the period of classic variographs (from October 1951 to August 2006), and automatically scaled afterwards using the 1 min digital FGE variometer files and FMI algorithm (Menvielle et al., 1995). Besides this change in the calculation methods, the following instrumental and methodological changes (see also Table 1 of metadata information) could have affected the integrity and homogeneity of the $\mathrm{K}$ index series: (1) according to the observatory's logbook, a change in the hand-scaled calculation method was applied in MayJune of 1985, though no further information is given; (2) the magnet suspension wire (originally of quartz) of the $H$ variograph broke for the first time in December 1979 and was replaced in the following month by a tungsten wire. This was accompanied by a change in the mean sensitivity of the variograph (from $\sim 4$ to $\sim 2 \mathrm{nT} \mathrm{mm}^{-1}$ ); (3) this suspension wire broke again in April 1984 and (4) February 1996, though no apparent changes in the variograph's sensitivity were registered in logbooks.

\section{Homogenization - main procedure}

There are two main types of homogeneity breaks that appear most often in geophysical records: (1) step-like jumps due to for example the change, repair or re-calibration of the instrument, the relocation of the instrument or the relocation of the station itself, and (2) trend-like changes of the base line due to for example gradual changes of the environment condition in populated regions or some continuous instrumental drift. Sparse and inaccurate measurements could be also a source of homogeneity breaks because low-quality data have more noise and bigger measurement errors. The simplest way to detect such inhomogeneities is a visual analysis (VA), preferably by an experienced person (Venema et al., 2012). However, because of its subjectivity, this analysis can be used only as a first and rough guide for the homogenization procedure providing information about "suspicious" periods. Afterwards, the series has to be examined through the use of objective statistical homogeneity tests (HTs). In this study we applied one of the most commonly used HTs - the standard normal homogeneity test (SNHT; Alexandersson and Moberg, 1997). This test supposes that analysed values are independent and identically normally distributed (null hypothesis). The alternative hypothesis assumes that the series has a jump-like shift (break). SNHT can be oversensitive to the breaks near the beginning and the end of the series (Costa and Soares, 2009). Alexandersson and Moberg (1997) proposed the use of a statistics $T(k)$ to compare the mean of the first $k$ years of the record with that of the last $(n-k)$ years, 
Table 1. A list of possible homogeneity breaks in COI Ki series for the period 1951 to 2012 found using metadata, visual analysis and statistical homogeneity tests. The last column shows values of $\langle\Sigma \mathrm{K}\rangle$ monthly used to correct detected breaks in COI Ki series, computed from comparison of TOL, EBR and COI values for periods between corrected breaks. Since the EBR series starts in January 1975, the correction value for the earlier period is estimated both using two reference series for the period 01/1975-12/1979 and using one reference series for the period 09/1951-12/1979. In both cases this correction is zero.

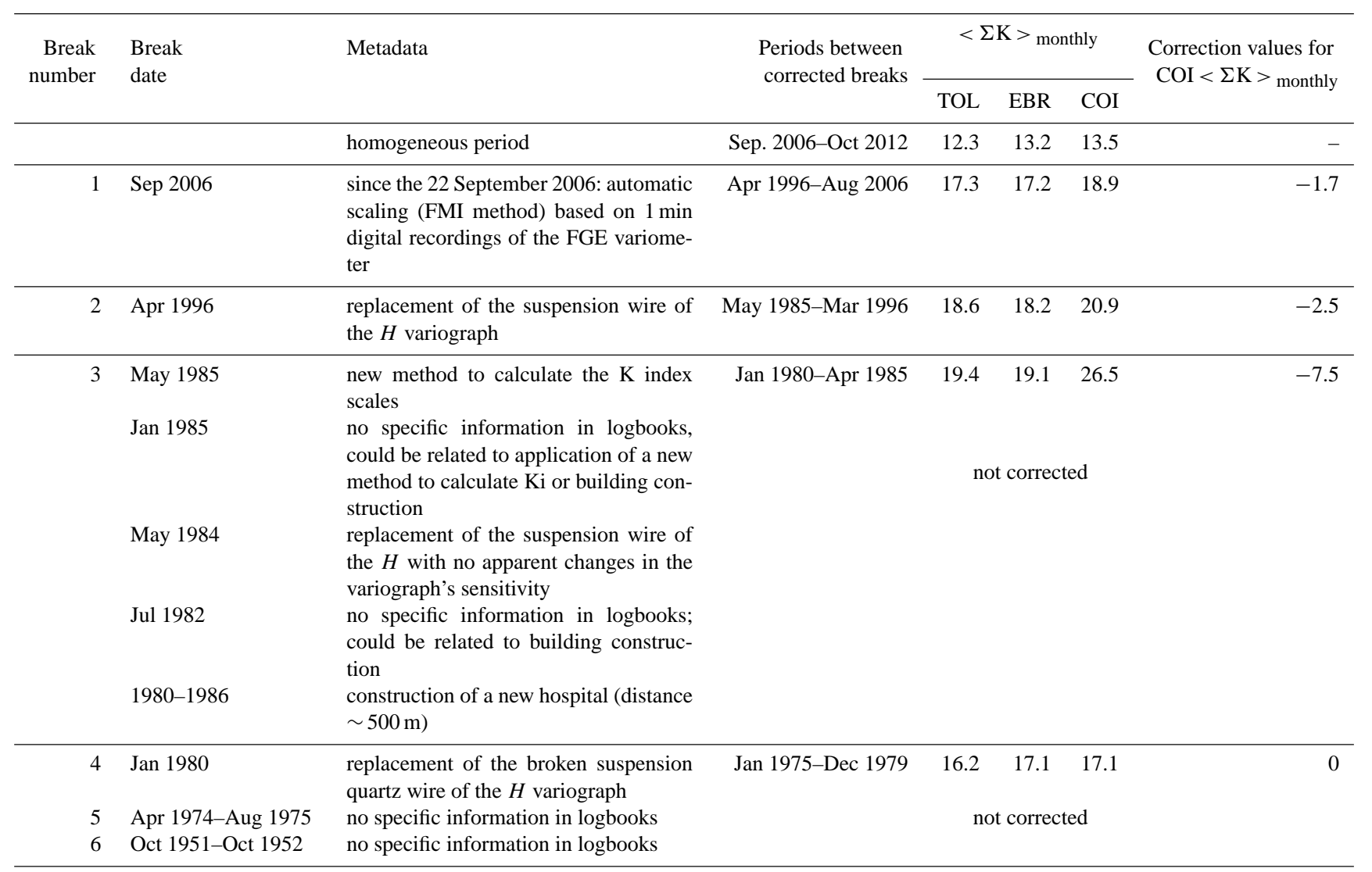

with $n$ the data set length:

$T(k)=k \bar{z}_{1}^{2}+(n-k) \bar{z}_{2}^{2}, \quad k=1 \ldots n$,

where

$\bar{z}_{1}=\frac{1}{k} \frac{\sum_{i=1}^{k}\left(Y_{i}-\bar{Y}\right)}{s}$,

$\bar{z}_{2}=\frac{1}{n-k} \frac{\sum_{i=k+1}^{n}\left(Y_{i}-\bar{Y}\right)}{s}$,

$s^{2}=\frac{1}{n} \sum_{i=1}^{n}\left(Y_{i}-\bar{Y}\right)^{2}$.

Here, $Y_{i}$ and $\bar{Y}$ are the $i$ th element and the mean value of the data set, respectively. If a break is located at the year $K$, then $T(k)$ reaches a maximum near the year $k=K$. The test statistics $T_{0}$ is defined as

$T_{0}=\max _{1 \leq k \leq n} T(k)$.

The null hypothesis is rejected if $T_{0}$ is above a certain level, which is dependent on the sample size. Critical values for different data set lengths are given in Khaliq and
Ouarda (2007). Therefore, the SNHT is a tool that not only estimates the level of inhomogeneity of the tested series for the tested period, but also detects the highly probable break points.

It has to be kept in mind that the relative amplitudes of $T(k)$ maxima, in general, do not correlate with the strength of corresponding HBs. Ratios of the amplitudes depend for example on the length of the studied period, distance between the breaks and proximity of the breaks to beginning/end of the series. Correction of a break can result in changes of the relative amplitudes of other breaks.

In a previous homogenization study (Morozova et al., 2012), we also used for geomagnetic data another homogeneity test - Buishand's cumulative deviation test (Buishand, 1982), and verified that its statistics was very similar to SNHT giving no additional information.

The HTs were applied in relative mode, i.e. to the difference between the COI series and corresponding reference series (RS), which are series of measurements of the same parameter from other stations or from some models. The HBs detected by the SNHT were cross-checked with 
available metadata and logbooks. Only breaks that coincide with known dates of instrumental, methodological or some other sort of registered changes in measuring conditions were corrected.

The corrections of the HBs have to be applied to the data series backward in time, starting from the most recent break. In this case all data are corrected in line with the conditions of the most recent homogeneous part of the data series: a period ranging from the last homogeneity break to the end of the series. The most usual way to correct breaks is to calculate the means of the studied parameter during some time before and some time after each of the breaks, and to use the differences between these means as the correction value. This is a procedure usually applied for homogenization of the meteorological data (Morozova and Valente, 2012). Unfortunately, this is not always the most adequate procedure when dealing with geomagnetic series, due to the presence of strong trends (as for the declination series) or periodicities (as for the geomagnetic $\mathrm{K}$ index series). The specific correction procedures applied in this study depend on the nature of the treated parameters and are described in Sects. 4.1 and 5.1 for the Ki and for the $D$ series, respectively.

To estimate the "quality" of the correction (Venema et al., 2012), the centred root mean square errors (CRMSEs, see e.g. Taylor, 2001) were calculated using reference series. The CRMSE parameter is calculated as

$\mathrm{CRMSE}^{2}=\sigma_{\mathrm{D}}^{2}+\sigma_{\mathrm{R}}^{2}-2 \sigma_{\mathrm{D}} \sigma_{\mathrm{R}} r$

where $\sigma_{\mathrm{D}}$ and $\sigma_{\mathrm{R}}$ are standard deviations of analysed and reference series, respectively, and $r$ is the correlation coefficient between analysed and reference series. When CRMSE values of corrected series are plotted vs. CRMSEs of original ones, dots on or below the bisector indicate the series with unchanged or improved (increased) homogeneity, while dots above the bisect indicate the series with decreased homogeneity. The reduction of the CRMSE values is used to confirm that the corrected series is more homogeneous than the original one (Venema et al., 2012).

The homogenization scheme can be summarized as follows:

1. visual analysis of the data; comparison to RS (available series from other stations or models);

2. application of homogeneity tests in, preferably, relative form;

3. detection of the HBs and comparison to available metadata and logbooks; selection of the breaks for correction;

4. correction of the breaks;

5. examination of the corrected series: VA, HTs, and CRMSE.

\section{Homogenization of local geomagnetic $K$ index series}

The series of monthly values of the local $\mathrm{K}$ index (COI Ki) for the period from 1951 to 2012 were already subjected to homogenization in Morozova et al. (2012). However, new digital data of COI Ki presently available, as well as new reference series obtained in the recent time, allowed us to perform a number of new tests and re-do the homogenization procedure with, as we hope, better quality results.

\subsection{Procedure}

The homogenization procedure for the Ki series followed the main scheme described above in Sect. 3. Preliminary analysis detected periods of anomalous behaviour of the local $\mathrm{Ki}$ compared to the reference series. These anomalies were cross-checked with the COI annual books and logbooks, and all found miscalculated values were corrected. The statistical homogeneity tests were then applied to the differences between COI Ki and reference series. The dates of possible breaks detected both by VA and HTs were compared with the COI logbooks and annual books, taking also into account the metadata available for the reference series. The significant breaks coinciding with dates of changes in the instruments or calculating methods were chosen for correction.

The correction values were calculated taking into account the differences between the original COI Ki series and reference series from the closest observatories for each of the corrected intervals. The corrected COI Ki series was tested using VA, HTs and CRMSE test.

\subsection{Data description}

The original Ki series consists of a number of values (integers in the range from 0 to 9), obtained from the largest range of geomagnetic disturbances in $D$ or $H$ during $3 \mathrm{~h} \mathrm{UT}$ intervals, using a conversion scale that is approximately logarithmic (e.g. Menvielle et al., 2011). The daily sum of the eight $3 \mathrm{~h}$ Ki values $(\Sigma \mathrm{K})$ and monthly means of this sum $(<\Sigma \mathrm{K}>$ monthly) have been previously used as representative of the irregular geomagnetic activity observed at a certain station (see e.g. Minamoto and Tagushi, 2009, or Zhang et al., 2008).

The original COI Ki series used in this study consists of data measured from October 1951 to October 2012 (10/1951-10/2012), has no extended gaps, and only a few daily sums are missing. During the measurement period some changes in the instruments and methodology took place. They are listed in Table 1. COI Ki is currently available in digital format for the whole period in the form of monthly means of daily sums $(<\Sigma \mathrm{K}\rangle$ monthly $)$. Therefore all results presented here were obtained using this parameter both for $\mathrm{COI} \mathrm{Ki}$ and for all reference series. 


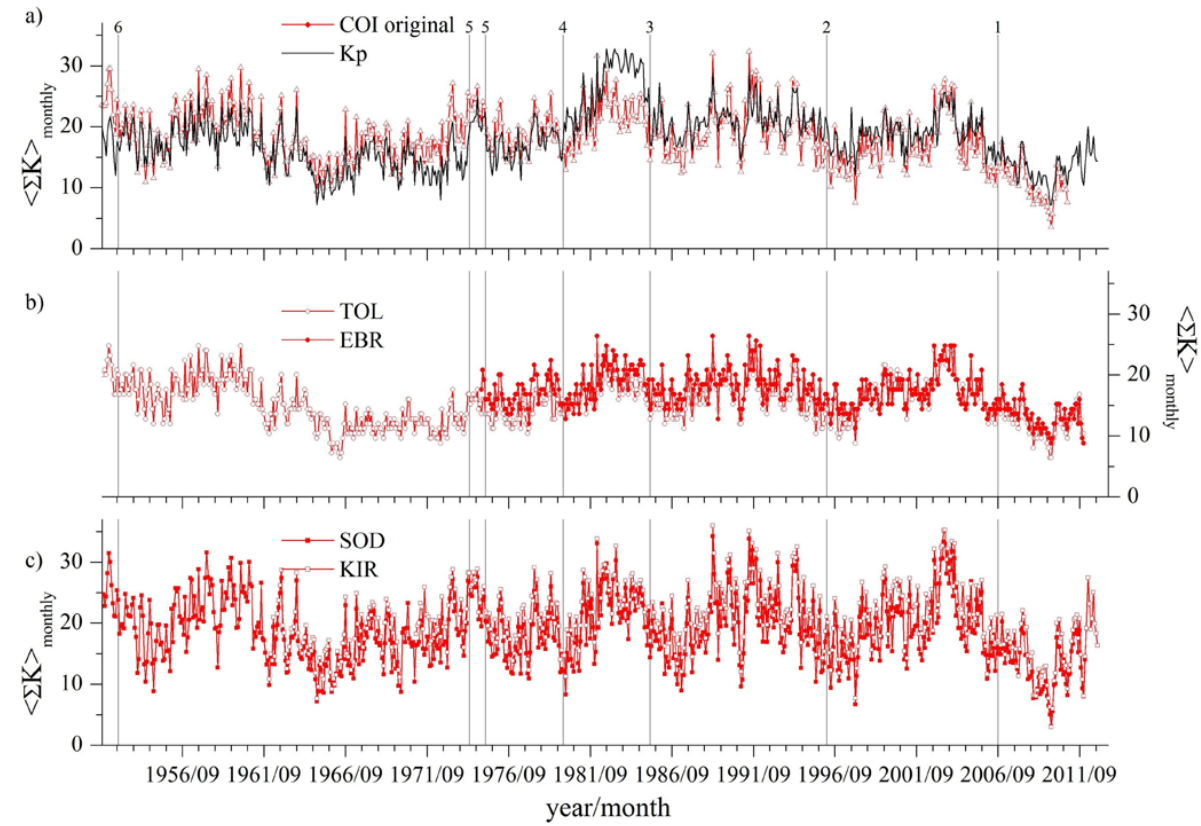

Fig. 1. Original COI Ki series (a) and references series: Kp (a), TOL Ki and EBR Ki (b), and SOD Ki and KIR Ki (c). Vertical lines mark periods of possible homogeneity breaks for COI data (see Table 1).

\subsection{Reference series}

The local $\mathrm{K}$ index series from four geomagnetic observatories and the planetary Kp index series were used as reference series (hereafter RS-Ki). The reference observatories are two closely located Spanish stations (Toledo - TOL and Ebro EBR) and two distant northern European stations (Sodankylä - SOD - in Finland and Kiruna - KIR - in Sweden). The periods of measurements and available metadata are presented in Table 2 for all RS-Ki. The original COI Ki and RS-Ki series are plotted in Fig. 1. The Spanish stations were preferred for their proximity to the COI station anticipating a strong similarity in the Ki variations. The Kp series was chosen because it describes global mean variations of the local $\mathrm{K}$ indices and has been widely tested. The series from the northern European stations are sufficiently long to test the homogeneity of the COI early measurements. They were also used to test the latitudinal effect in the variations of the geomagnetic indices.

Inevitably, a number of instrumental changes and station re-locations occurred in all observatories. The application of necessary corrections is specified in the station metadata (see links in Table 2 and Menvielle et al., 2011, for Kp). Unfortunately, the series from one of the closest and one of the most useful stations (TOL) has at least one significant artificial break in 1998, possibly associated with the transition from manual to automatic methods of Ki calculation. The preliminary COI Ki homogenization procedure showed the need for correction of this break in TOL Ki series. The homogeneity tests were applied to TOL Ki series itself as well as to the differences between TOL Ki and series of Ki from the closest stations (EBR, COI and the Italian AQU station - see Table 2) for short homogeneous periods (different for each of the stations) around 1998. These HTs (Fig. 2, thin lines) showed a significant break around January 1998. This break is also clearly seen through VA (not shown here): in January 1998 there is a jump of $\mathrm{Ki}$ of about 2 units. We corrected this jump. The corrected TOL Ki series shows no significant homogeneity break (see Fig. 2, thick lines; see also Sect. 4.6 for additional discussion). Hence, all the results presented below were obtained using the corrected TOL Ki series.

All reference series were used for relative homogeneity analysis so that the series of differences between $\mathrm{COI} \mathrm{Ki}$ and the five RS-Ki (three of these difference series are presented in Fig. 3) were studied both with VA and with HTs. Also, the absolute HTs (HTs applied to the series themselves) were carried out to obtain and compare the internal variability of $\mathrm{K}$ indices due to geomagnetic activity cycles. They are discussed in Sects. 4.4 and 4.6.

\subsection{Homogeneity breaks}

As one can see from Fig. 1, the Ki series have a significant variability both on month-to-month and on decadal timescales. The latter depicts the quasi-11-year solar cycle, especially the last three cycles. However, geomagnetic activity peaks seen in Fig. 1 do not coincide with the maxima of sunspot numbers, which occurred around 1980, 1990 and 2000 for cycles 21,22 and 23, respectively. In fact, the strongest events of the geomagnetic activity take place during the declining phase of the solar activity or close to the 
Table 2. A list of reference series used for COI Ki homogenization.

\begin{tabular}{|c|c|c|c|c|c|c|}
\hline & $\begin{array}{l}\text { Station } \\
\text { name }\end{array}$ & $\begin{array}{l}\text { Station } \\
\text { code }\end{array}$ & Country & $\begin{array}{l}\text { Latitude, } \\
\text { deg min }\end{array}$ & $\begin{array}{c}\text { Longitude, } \\
\text { deg min }\end{array}$ & $\begin{array}{l}\text { Available data, } \\
\text { comments }\end{array}$ \\
\hline 1 & Toledo $^{1}$ & TOL & Spain & 3933 & 0421 & $\begin{array}{l}\text { Jan } 1951-\text { Dec } 2011 \\
\text { metadata: } 1982 \text { - re-location; from } 1998 \text { onwards - automatic } \\
\text { calculation of Ki } \\
\text { no correction applied }\end{array}$ \\
\hline 2 & Ebro $^{2}$ & EBR & Spain & 4048 & 0030 & $\begin{array}{l}\text { Jan } 1975-\text { Dec } 2011 \\
\text { gap: Jan } 1989 \text { - no data, linear interpolation } \\
\text { metadata: } 2000 \text { - digital format }\end{array}$ \\
\hline 3 & Sodankylä ${ }^{3}$ & SOD & Finland & 6722 & 2638 & $\begin{array}{l}\text { Jan } 1914-\text { Feb } 2012 \\
\text { gap: Jun } 1953 \text { - no data, linear interpolation } \\
\text { metadata: } 1936,1986,2003 \text { - changes of instruments; correc- } \\
\text { tions are applied }\end{array}$ \\
\hline 4 & Kiruna $^{4}$ & KIR & Sweden & 6750 & 2025 & $\begin{array}{l}\text { Jan 1962-Apr } 2013 \\
\text { gap: Feb } 1970-\text { Dec } 1970 \text { - no data }\end{array}$ \\
\hline 5 & $\mathrm{Kp}^{5}$ & $\mathrm{Kp}$ & planetary & - & - & Jan 1932-Dec 2010 \\
\hline 6 & L'Aquila ${ }^{6}$ & AQU & Italy & 4223 & 1319 & $\begin{array}{l}\text { Jan 1988-Dec } 2010 \\
\text { note: Jan 1996-Mar } 1996 \text { - outliers; origin is not identified }\end{array}$ \\
\hline
\end{tabular}

Metadata: ${ }^{1}$ http://www.ign.es/ign/resources/geomagnetismo/observatorios/RESENA_SAN_PABLO.pdf; ${ }^{2}$ http://www.obsebre.es/php/geomagnetisme.php;

${ }^{3} \mathrm{http}: / /$ www.sgo.fi/Data/Magnetometer/magnHistory.php; ${ }^{4} \mathrm{http}: / /$ www.irf.se//Observatory/?link[Magnetometers]=Description;

5 http://www-app3.gfz-potsdam.de/kp_index/index.html or http://isgi.cetp.ipsl.fr/deskp_ind.html;

${ }^{6} \mathrm{http}: / /$ roma2.rm.ingv.it/en/facilities/geomagnetic_observatories/14/1-aquila_magnetic_observatory
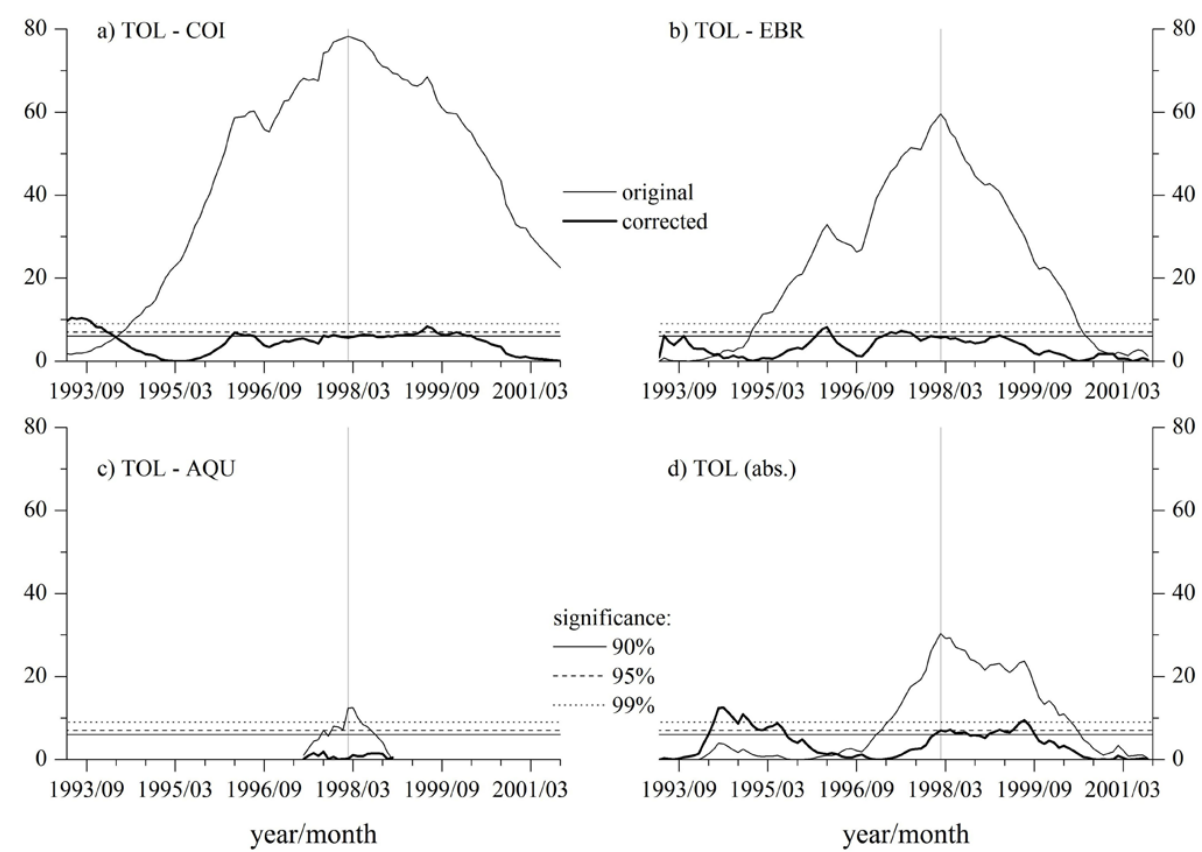

Fig. 2. Homogeneity test statistics for TOL Ki in relative (compared to Ki from COI (a), EBR (b), AQU (c)) and in absolute (d) modes around the 1998 epoch. Thin lines - before correction; thick lines - after correction. Significance levels are marked by horizontal lines. Vertical grey line shows the break date for TOL series.

minimum (Du, 2011). Besides, Love (2011) showed an increase of the mean level of geomagnetic activity over the past $141 \mathrm{yr}$. These features are seen not only in the Ki series itself (Figs. 1 and 3) but also in the homogeneity test statistics (Fig. 4). As quasi-regular cycles are considered by the HTs as a sequence of periods of upward/downward trends, HT statistics peaks somewhere between minima and maxima of the cyclic series. This makes the absolute HTs less efficient in detecting artificial homogeneity breaks of geomagnetic parameters than in the case of meteorological ones. Besides, 

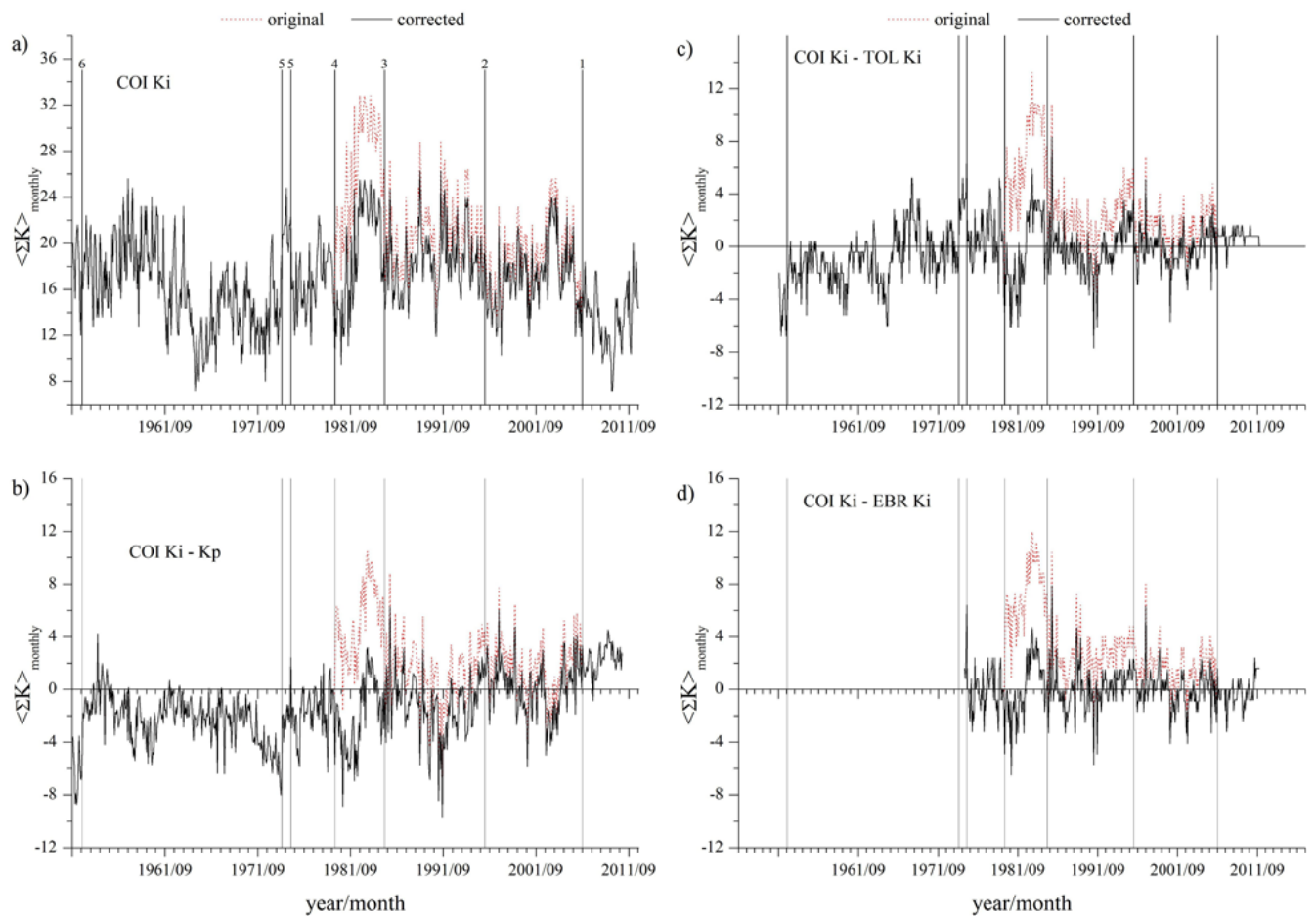

Fig. 3. Original (red dashed lines) and corrected (black solid lines) series for COI Ki (a), and for differences between COI Ki and reference series: Kp (b), TOL Ki (c) and EBR Ki (d). Vertical lines mark the dates of the breaks (see Table 1).

since the amplitude of the local Ki variations depends not only on the sensitivity of the local instruments but also on the local geomagnetic environment, which in turn depends on the latitude, the relative variations of the local Ki from distant stations could depend on time and increase during the maxima of the geomagnetic cycle. Therefore, even the relative HTs could pick up the features related to the quasi-11year geomagnetic cycles. This effect is expected to be weaker for relative HTs, when data from close positioned stations are used, than when one uses data from more distant stations. In any case, when applying the HTs to the Ki series, one has to keep in mind that some of the detected HBs may be due to natural cycles.

Figure 4 shows the SNHT statistics for the relative and absolute homogeneity tests (lines with and without dots, respectively). The most significant HBs are coincident with known changes in the COI $\mathrm{Ki}$ measurement routines: replacement of the broken wire in 1980 (break \#4), change of the calculation method in May 1985 or June 1985 (break \#3), change of the variograph wire in 1996 (break \#2) and start of automatic Ki calculation in 2006 (break \#1). These breaks are seen in the absolute HTs of COI Ki as well (Fig. 4c). Unfortunately, not all events listed in Table 1 (column "metadata") are clearly seen in HT statistics being either (1) relatively small or (2) close to the maxima of geomagnetic cycle. However, they are seen quite well in VA (Fig. 3) and appear in intermediate homogeneity tests of partly corrected COI Ki series (not shown here).

\subsection{Correction of the breaks}

The four homogeneity breaks (numbers 1, 2, 3 and 4) were chosen for correction. Other events listed in Table 1 are either not seen in the VA and HTs simultaneously or do not coincide with known changes in the instruments or measurement/computation procedures (breaks \#5 and \#6). The HB \#6, for instance, could be related to the early period of about 12 months when the procedures for the measurement and calculation of Ki were not fully established.

The corrections for the above-mentioned HBs were calculated using the closest stations of TOL and EBR as references and based on the assumption that the difference of $<\Sigma \mathrm{K}\rangle$ monthly between so closely located stations would not exceed 1-1.5 (which is clearly true for the pair TOLEBR - see Table 1). The exact correction values in Table 1 are chosen so that the corrections for the monthly sums of $\Sigma \mathrm{K}(30 \times<\Sigma \mathrm{K}>$ monthly $)$ are integer values. The corrected series of COI Ki is shown in Fig. 3 together with the differences between the corrected COI Ki and three RS-Ki series.

Relative homogeneity tests performed on corrected series (Fig. 4, thick lines with dots) show that, relatively to the closest Spanish stations of TOL and EBR, the corrected COI $\mathrm{Ki}$ series has no significant homogeneity breaks around the known dates of instrument or procedure changes. However, 

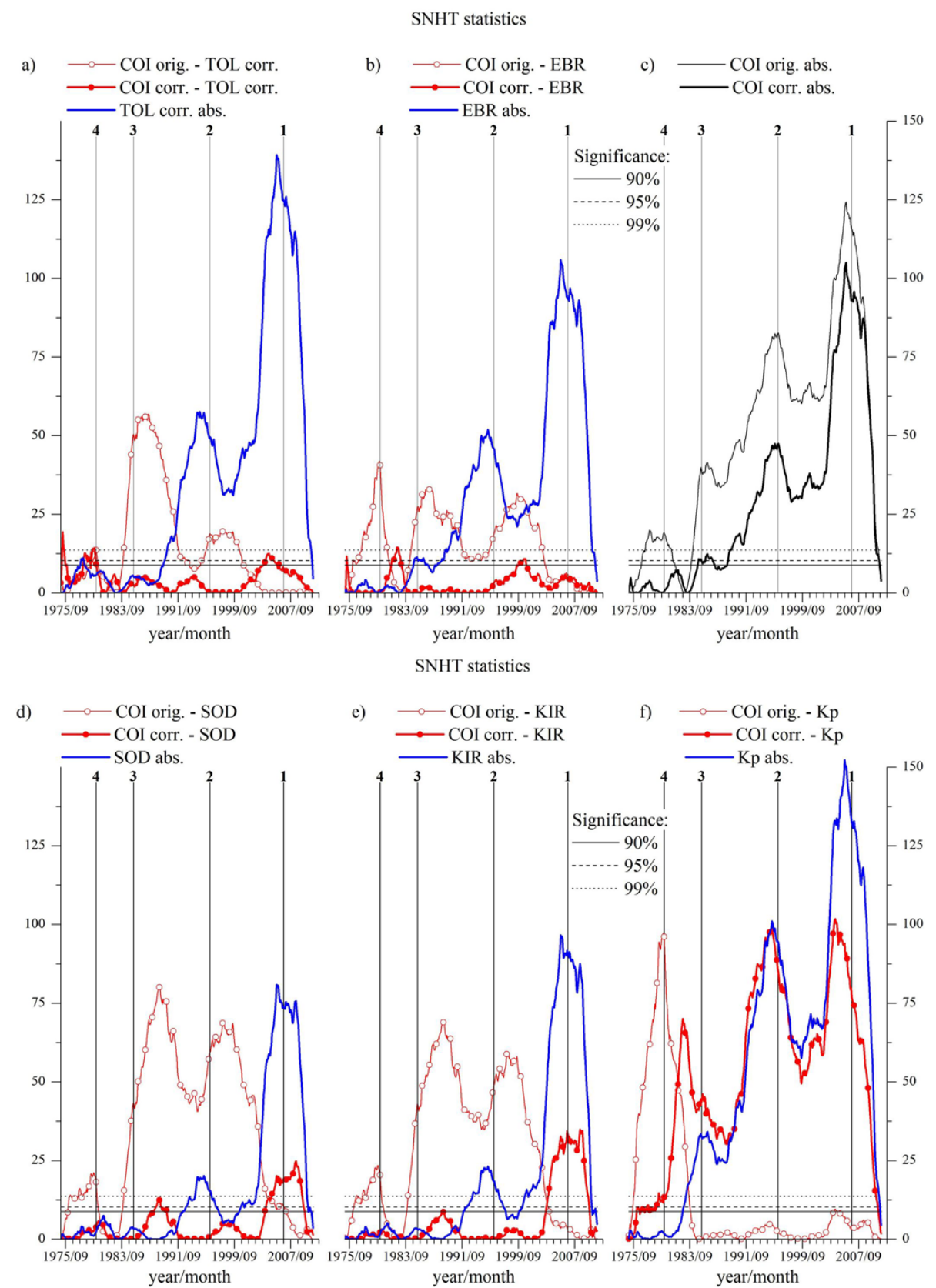

Fig. 4. Homogeneity test statistics of COI Ki in relative (compared to TOL Ki (a), EBR Ki (b), SOD Ki (d), KIR Ki (e) and Kp (f)) and absolute (c) modes for the period from 1975 to 2010. Absolute test statistics are shown by lines without dots. Thin lines - before correction, thick lines - after correction. Vertical lines mark periods of possible homogeneity breaks for COI data (see Table 1). Significance levels are marked by horizontal lines.

there still exist homogeneity breaks found by absolute tests, which could be associated with the coming out features of the geomagnetic cycles (Fig. 4, thick lines without dots). The differences between corrected COI Ki and the distant northern European stations (SOD and KIR) Ki series as well as the Kp series also show a significant homogeneity break around 2005 (Fig. 4, thick lines with dots), which, additionally, coincides with a peak of the absolute HT statistics. We interpret these features as the difference in the geomagnetic field response to the developing geomagnetic cycles between COI and higher-latitude stations such as SOD, KIR and those used to calculate $\mathrm{Kp}$. This hypothesis is supported by the similarities between the statistics of relative and absolute HTs (thick lines on Fig. 4). 


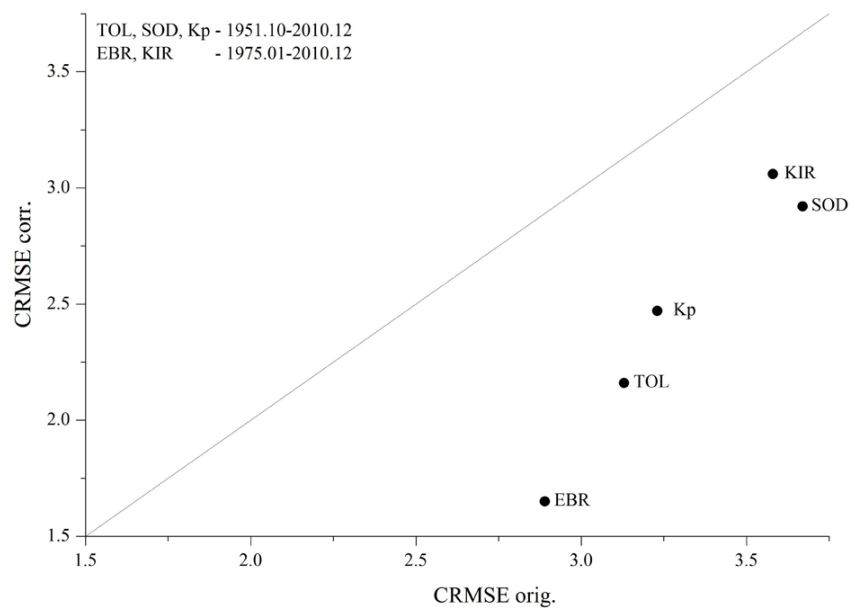

Fig. 5. CRMSE of corrected vs. original COI Ki series.

The CRMSE values were calculated to estimate the change of the homogeneity level after applying the correction (Fig. 5). As one can see, the homogeneity level of COI $\mathrm{Ki}$ series increased after correction relatively to all reference series.

\subsection{New information provided by the homogenized series}

The increasing trend of the aa index during the 20th century has been widely discussed and considered representative of a gradual increase in geomagnetic activity (e.g. Martini and Mursula, 2008; Love, 2011). Analysis was also made directly on $\mathrm{K}$ index series, leading to a similar conclusion that geomagnetic activity has increased over the past $141 \mathrm{yr}$, although not monotonically (Love, 2011; Love et al., 2012). Since solar cycle 14 in the beginning of the 20th century, a gradual increase until 1960 and then a strong dropout in the early 1960s have been reported, followed by a weaker increasing trend from around 1963 until nowadays (Martini and Mursula, 2008; Love, 2011). Furthermore, it has been noticed that the observed increase varies with latitude, being largest at high latitudes, smaller at low latitudes and smallest at midlatitudes (Martini and Mursula, 2008). We expect that the Ki corrected series for COI, and the corresponding differences relative to reference series may confirm or even bring further details to these results.

Figure 4 shows statistics of absolute HTs of all RS-Ki and $\mathrm{COI} \mathrm{Ki}$ series (thick lines without dots). The peaks of statistics mark maxima around 1985, 1995 and 2005, which seem to correlate with global maxima of geomagnetic activity as seen in the aa index series (e.g. see Fig. 3 in Du, 2011). Moreover, the prolonged minimum of the geomagnetic activity that took place in 1960s-1970s is also present as a period of relatively small peaks of the HT statistics. The rising of the peaks' amplitude to the end of the 20th century, quite probably, reflects the growing strength of the geomagnetic cycles

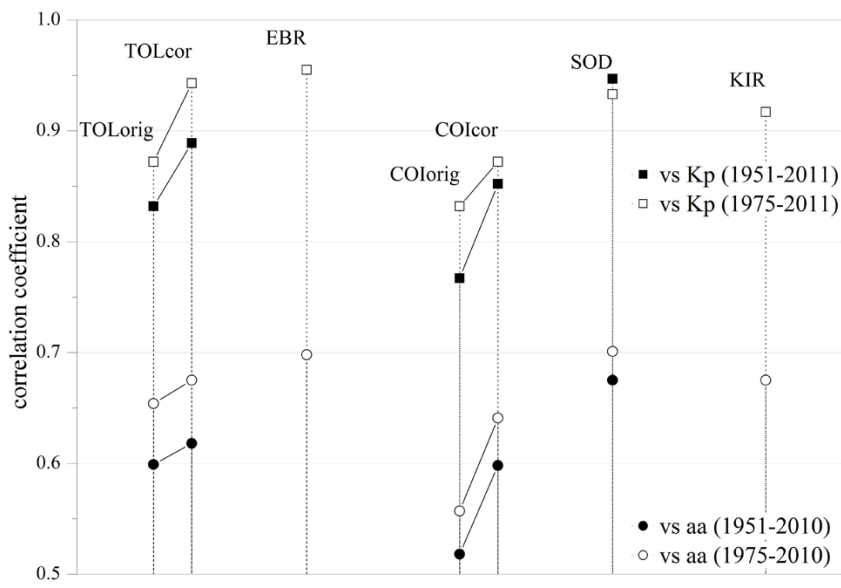

Fig. 6. Correlation coefficients between the local Ki series from five stations and two global geomagnetic indices, Kp (squares) and aa (circles), calculated for two periods: 1975-2010/2011 (open symbols) and 1951-2010/2011 (filled symbols). Results using the original and corrected series of both COI Ki and TOL Ki are shown.

reaching the highest level around 2005. When comparing series from different observatories, the cycles disappear if the observatories are close in latitude, but the 2005 maxima remain present if they are not, in agreement with previously observed latitude dependence of the increasing geomagnetic activity.

In Fig. 6 we compare variations of the original and corrected (both $\mathrm{COI}$ and TOL) $\mathrm{Ki}$ series with the changes of two global geomagnetic indices: $\mathrm{Kp}$ and aa (the latter is available for example at ftp.ngdc.noaa.gov/STP/ GEOMAGNETICDATA/INDICES). The correlation coefficients between corrected local and global indices increase compared to the correlation coefficients for uncorrected series. Figure 6 also shows results for the other three observatories used in this study - EBR, SOD and KIR. The correlation between $\mathrm{Kp}$ (or aa) and corrected COI Ki is still lower than for other local indices. The reason for that is seen in Fig. 7 showing the running correlation coefficients between local indices and $\mathrm{Kp}$ for a window of 132 months. Although the corrected COI Ki (Fig. 7a) has no longer dramatic decreases of correlation as was the case for the original one (Fig. 7b), the correlation between the $\mathrm{COI} \mathrm{Ki}$ and $\mathrm{Kp}$ is still quite low during the 1970-1990 period. This can be due to the presence of unregistered (and therefore impossible to correct) changes in the instruments during this period, as shown in Table 1.

Another interesting feature is the period of very low correlation between TOL Ki and Kp around 1965-1968. This low-correlation period is also seen in COI data though not as prominent, and it is practically absent in SOD data. Whether it is a result of some local mid-latitude effect is not known. Also note the improvement of the correlation between TOL $\mathrm{Ki}$ and Kp around 1998, after applying to the original TOL series the correction discussed in Sect. 4.3. 

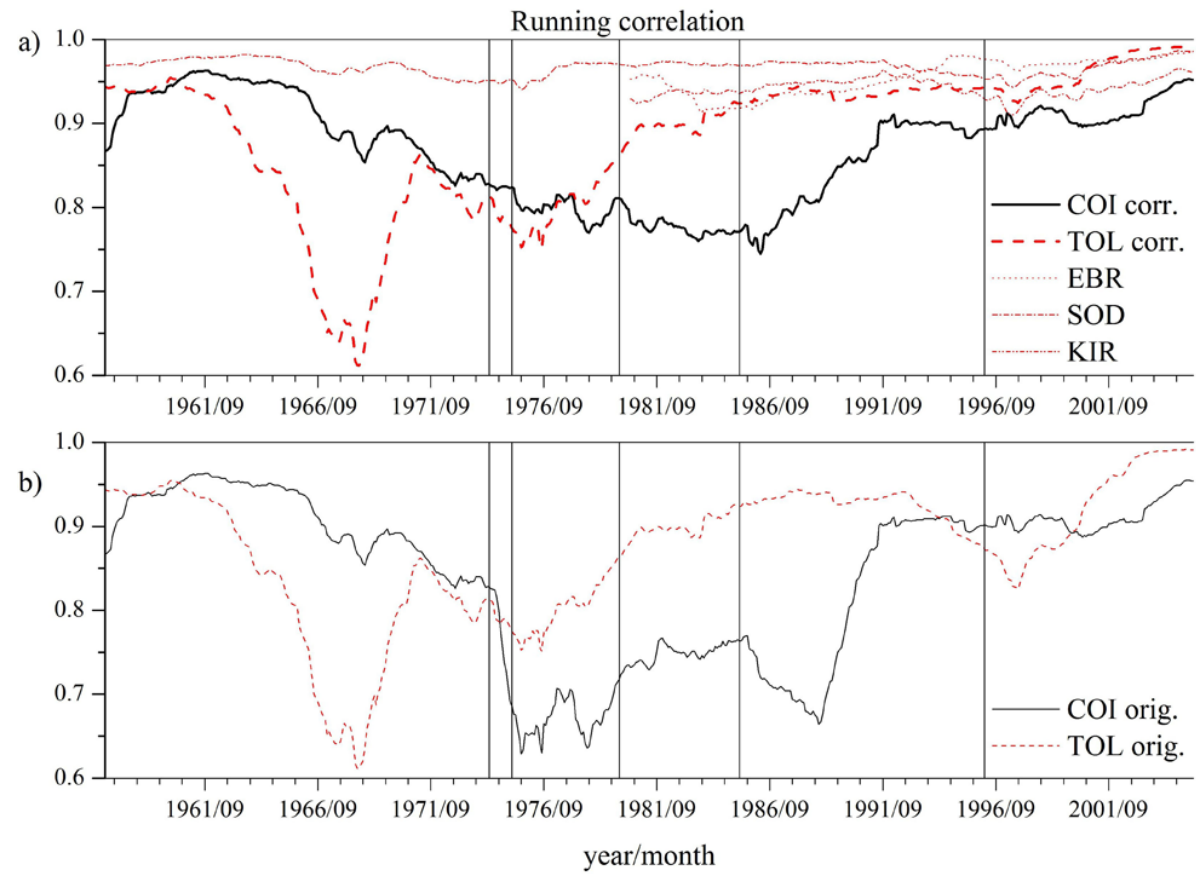

Fig. 7. Running correlation (window width 132 months $=11 \mathrm{yr}$ ) between the Ki series from five stations and Kp: (a) corrected COI, corrected TOL, EBR, SOD and KIR Ki series, (b) original COI and original TOL Ki series. Vertical lines mark periods of possible homogeneity breaks for COI data (see Table 1).

\section{Homogenization of local geomagnetic declination series}

\subsection{Procedure}

The $D$ component monthly series obtained at $\mathrm{COI}$ is, among all other local geomagnetic elements series, the one with fewer breaks since the beginning of COI activity. As typical for geomagnetic elements time series on centennial timescales, it shows a strong trend, linear at first sight (see Fig. 8, top panel). This makes this kind of series very different from both meteorological parameters to which homogeneity tests have been largely applied and from Ki series, described in Sect. 4. The almost linear trend does not allow one to use the homogeneity tests on $D$ series, because it will dominate all possibly existing inhomogeneities, making them undetectable by the HTs. It is possible, of course, to detrend the $D$ series, but we decided instead to use a parameter that has a well-known physical meaning: the "secular variation" (SV) of $D$, which is the first time derivative of $D$, usually calculated for annual data series as the time series of differences of consecutive values.

Given that the available COI $D$ data have monthly resolution, we calculated the first time derivative using the monthly $D$ series in two ways:
1. as a difference between two consecutive months ("month-to-month" derivative, hereafter " $\mathrm{m} 2 \mathrm{~m}$ $\mathrm{d} D / \mathrm{d} t "):$

$$
\begin{gathered}
\mathrm{m} 2 \mathrm{~m} \mathrm{~d} D / \mathrm{d} t \text { (year, month })=(D(\text { year, month }) \\
-D(\text { year, month }-1)) /(1 / 12) .
\end{gathered}
$$

2. as a difference between the same months of two consecutive years ("year-to-year" derivative, hereafter "y $2 \mathrm{y} \mathrm{d} D / \mathrm{d} t$ "):

$$
\begin{gathered}
\text { y2y d } D / \mathrm{d} t(\text { year, month })=(D(\text { year, month }) \\
-D(\text { year }-1, \text { month })) / 1 .
\end{gathered}
$$

For all data series that originally have annual resolution, the first time derivative of $D$ is calculated as

$$
\begin{gathered}
\text { y2y } \mathrm{d} D / \mathrm{d} t(\text { year })=(D(\text { year }) \\
-D(\text { year }-1)) / 1
\end{gathered}
$$

and then linearly interpolated to monthly timescale.

Both $\mathrm{m} 2 \mathrm{~m}$ and $\mathrm{y} 2 \mathrm{y}$ derivatives have unities of "degree per year". The $\mathrm{m} 2 \mathrm{~m}$ derivative shows rapid variations on the monthly timescale, and its outliers mark sudden changes in the $D$ slope. In this series, the ratio of noise to SV signal is very high. The y2y derivative (Fig. 8, bottom panel) gives a better account of the SV signal, with monthly time resolution. It is equivalent to applying a 12-month moving average 


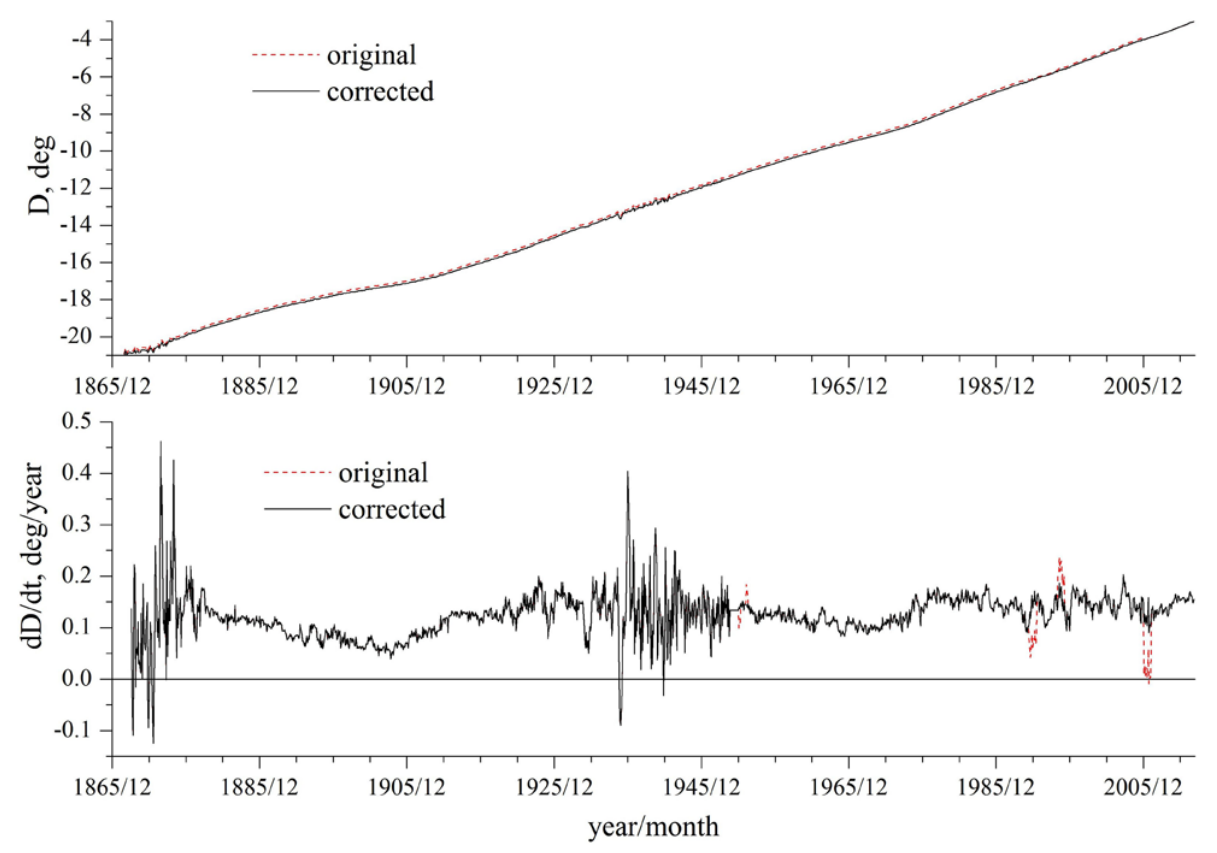

Fig. 8. Original (red dashed lines) and corrected (black solid lines) series of COI $D$ (top panel) and its SV (bottom panel) from 1867 to 2012.

to the $\mathrm{m} 2 \mathrm{~m}$ series. In this way, the annual variation associated with external currents is filtered out though the monthly resolution is kept (see e.g. Olsen and Mandea, 2007). This series does not have dominating trends and can be used in statistical homogeneity tests. While making the homogeneity analysis with derivatives, one has to keep in mind that the physical meaning of the breaks in the studied $D$ component series itself and the breaks in the first derivative are different. In the former case, the breaks detected by the HTs can be associated with trends or shifts, and as already explained natural trends are expected in the $D$ series. In the latter case, the HBs can be related also to outliers (sudden changes of the slope of the $D$ series) and changes of the trend of the derivative (change of the curvature of the $D$ series).

In the case of $D$ series, the quality of the data does not allow us to correct the breaks that took place before 1951 (see Sect. 2 for the history of the COI observatory). As one can see in Fig. 8, there are two periods of high amplitude random fluctuations in $\mathrm{y} 2 \mathrm{y} \mathrm{d} D / \mathrm{d} t$ : from the beginning until ca. 1876 and between 1930 and 1950, due to noisy and unreliable $D$ data. We note that the fluctuations shown in Fig. 8 are far greater than the expected scatter due to limited precision of the instruments: the unifilars magnetometers of Gibson (1867-1875) and of Elliott (1875-1955) had errors of $\sim 8 \times 10^{-3}$ degrees, and the Askania declinometer had errors of $\sim 3 \times 10^{-3}$ degrees. The DI-flux presently in use has associated errors of only $\sim 3 \times 10^{-4}$ degrees. These fluctuations do not allow us to calculate consistent corrections or even base line for $D$ series before the 1951. Therefore, in this study the breaks that took place before 1951 were left uncorrected.
The correction procedure was applied using both $D$ and $\mathrm{d} D / \mathrm{d} t$ series in order to determine more accurately the HB dates and calculate more reliable corrections. When the correction was applied to $\mathrm{d} D / \mathrm{d} t$ series, the $D$ series was recalculated from the corrected first derivative monthly series starting from the most recent data back to the beginning of the series.

\subsection{Data description}

The $D$ component series used in this study consists of data measured from July 1967 to October 2012 (07/186710/2012). The original series has 21 gaps having a total of 31 monthly data missing (1.78\% of the whole series length). There are three big gaps 3 months long, four gaps 2 months long and 14 one-month-long gaps. All gaps were linearly interpolated. During the measurement period, some changes in the instruments and one station relocation took place. These events are listed in Table 3. The original $D$ and $\mathrm{y} 2 \mathrm{y} \mathrm{d} D / \mathrm{d} t$ series are shown in Fig. 8 by dashed lines.

\subsection{Reference series}

Two types of reference series were used to homogenize the $D$ component data series: annual means of $D$ measurements from 16 African and European geomagnetic observatories and two series of annual values of $D$ calculated for Coimbra using geomagnetic field models. The observatories are listed in Table 4. These data were obtained from the British Geological Survey database (http://www.geomag.bgs.ac.uk/ data_service/data/annual_means.shtml). The selected stations have at least 20-year-long series of the $D$ component 
Table 3. A list of possible homogeneity breaks in COI $D$ series for the period 1867 to 2012 found using metadata, visual analysis and statistical homogeneity tests. Only breaks after January 1951 were corrected. Correction values and correction methods for the periods between breaks are indicated in columns 5 and 6 .

\begin{tabular}{|c|c|c|c|c|c|}
\hline $\begin{array}{r}\text { Break } \\
\text { number }\end{array}$ & $\begin{array}{l}\text { Break } \\
\text { date }\end{array}$ & Metadata & $\begin{array}{l}\text { Periods between } \\
\text { corrected breaks }\end{array}$ & $\begin{array}{l}\text { Series used for } \\
\text { correction calculations }\end{array}$ & $\begin{array}{l}\text { Correction values } \\
\text { for } D, \text { min }\end{array}$ \\
\hline & & homogeneous period & Jan 2006-Oct 2012 & & - \\
\hline 1 & Jan 2006 & $\begin{array}{l}\text { new instrument was installed in Jun } 2006 \text {; the } \\
\text { correction of }-6^{\prime} \text { was applied to the data start- } \\
\text { ing in Jan } 2006\end{array}$ & Apr 1994-Dec 2005 & $D$ series & -6 \\
\hline 2 & Jun 2003 & $\begin{array}{l}\text { change of the suspension wire; correction al- } \\
\text { ready applied }\end{array}$ & & not corrected & \\
\hline 3 & Jan 1998 & no specific information & & & \\
\hline 4 & May 1994 & change of the suspension wire & Jul 1990-Mar 1994 & $\mathrm{~m} 2 \mathrm{~m} \mathrm{~d} D / \mathrm{d} t$ series & -3 \\
\hline 5 & Jun 1990-Jul 1990 & $\begin{array}{l}\text { small instrumental problems and construction } \\
\text { in the nearby area }\end{array}$ & $\begin{array}{l}\text { Apr 1951-May } 1990 \\
\text { Jun } 1990\end{array}$ & $\mathrm{~m} 2 \mathrm{~m} \mathrm{~d} D / \mathrm{d} t$ series & $\begin{array}{l}-7.55 \\
-5.025\end{array}$ \\
\hline 6 & May 1989 & same as previous & & not corrected & \\
\hline 7 & Jun 1983 & no specific information & & & \\
\hline 8 & Sep 1977 & no specific information & & & \\
\hline 10 & Oct 1951 & $\begin{array}{l}\text { installation of a new declinometer (Askania) - } \\
\text { after comparison with former Elliott no signifi- } \\
\text { cant differences were found } \\
\text { reinstallation of variographs; new routines for } \\
\text { absolute measurements; }\end{array}$ & & & \\
\hline 11 & Jan 1951-Mar 1951 & end of interpolation period & Mar 1951 & $D$ series & -5.7 \\
\hline & & & Feb 1951 & & -5.85 \\
\hline & & & Jan 1951 & & -5.1 \\
\hline 12 & Oct $1948-$ Dec 1950 & $\begin{array}{l}\text { no measurements, data in the annual books were } \\
\text { interpolated }\end{array}$ & & & \\
\hline 13 & Jul 1937-Oct 1941 & no specific information is found, but data are & & & \\
\hline & & $\begin{array}{l}\text { noisy; in Jan } 1938 \text { the new procedure to com- } \\
\text { pute the data was applied }\end{array}$ & Jul 1867-Dec 1950 & no other corrections & -7.55 \\
\hline 14 & Jan 1932 & re-location of the magnetic observatory & & & \\
\hline 15 & Jan 1930 & $\begin{array}{l}\text { no specific information, may be related to tram } \\
\text { line installation }\end{array}$ & & & \\
\hline 16 & Jan 1919 & new procedure to compute the data was applied & & & \\
\hline 17 & Jan 1878 & Unifilar magnetometer of Elliott was installed & & & \\
\hline 18 & Jul? 1875 & $\begin{array}{l}\text { new method to calculate } D \text { was applied; new } \\
\text { azimuth mark was calculated }\end{array}$ & & & \\
\hline 19 & Jul 1866-Jun 1874 & $\begin{array}{l}\text { no specific information, but data are noisy, } \\
\text { probably, due to inaccurate local azimuth deter- } \\
\text { mination (see text) }\end{array}$ & & & \\
\hline
\end{tabular}

and do not show undocumented homogeneity breaks. Some of these series originate from a set of closely located observatories (cases 2, 5 and 9) or have breaks due to instrument changes. In such cases the necessary corrections, provided by the same database, were applied, and individual series were combined into composite ones. The first derivatives (SV) were calculated for all reference series from the annual means using Eq. (9), and a final reference $\mathrm{d} D / \mathrm{d} t$ series (hereafter "RS ${ }^{\text {obs }}-D$ ") was computed as the mean of all 16 individual SV series interpolated to monthly timescale (Fig. 9 and thick blue line in Fig. 10).

Two geomagnetic field models were used to obtain a second type of reference series: (1) the COV-OBS model (Gillet et al., 2013), hereafter called "COV-OBS w COI", was computed using data of observatory annual means for the 1840-2010 period, COI values included, provided by the World Data Center for Geomagnetism; (2) a second model, hereafter called "COV-OBS w/o COI", was computed by $\mathrm{N}$. Gillet for this study, and differs from COV-OBS only in that the input data set excludes COI data. The first derivatives of annual values produced by both COV-OBS w COI and COV-OBS w/o COI were calculated using Eq. (9). The resulting two series, interpolated to monthly timescale, are used as the second type of reference series, $\mathrm{RS}^{\mathrm{w}} \mathrm{COI}-D$ and $\mathrm{RS}^{\text {w/o }}{ }^{\mathrm{CO}}-D$, respectively (see lines with dots in Fig. 10).

All reference series $\left(\mathrm{RS}^{\text {obs }}-D, \mathrm{RS}^{\mathrm{w}} \mathrm{COI}_{-} D\right.$ and $\mathrm{RS}^{\mathrm{w} / \mathrm{o}} \mathrm{COI}_{-} D$ ) show good agreement with $\mathrm{COI} \mathrm{y} 2 \mathrm{y}$ $\mathrm{d} D / \mathrm{d} t$ variations in Fig. 10. Most significant dissimilarities were found for two periods: from 1867 to 1876 and from 1930 to 1950 . The $D$ data for these periods have significant month-to-month variations as already said (see $\mathrm{m} 2 \mathrm{~m} \mathrm{~d} D / \mathrm{d} t$ in Fig. 10, top panel, and also $D$ series in Fig. 8, top panel). There are also a number of outliers in $\mathrm{m} 2 \mathrm{~m} \mathrm{~d} D / \mathrm{d} t$ corresponding to shifts in $\mathrm{y} 2 \mathrm{y} \mathrm{d} D / \mathrm{d} t$ series. Most of these 
Table 4. A list of European and African stations used to obtain the reference series for COI $D$. Some stations have changes in the instruments and/or were re-located. The first and last years of each whole set are in bold, and intermediate dates are in italic.

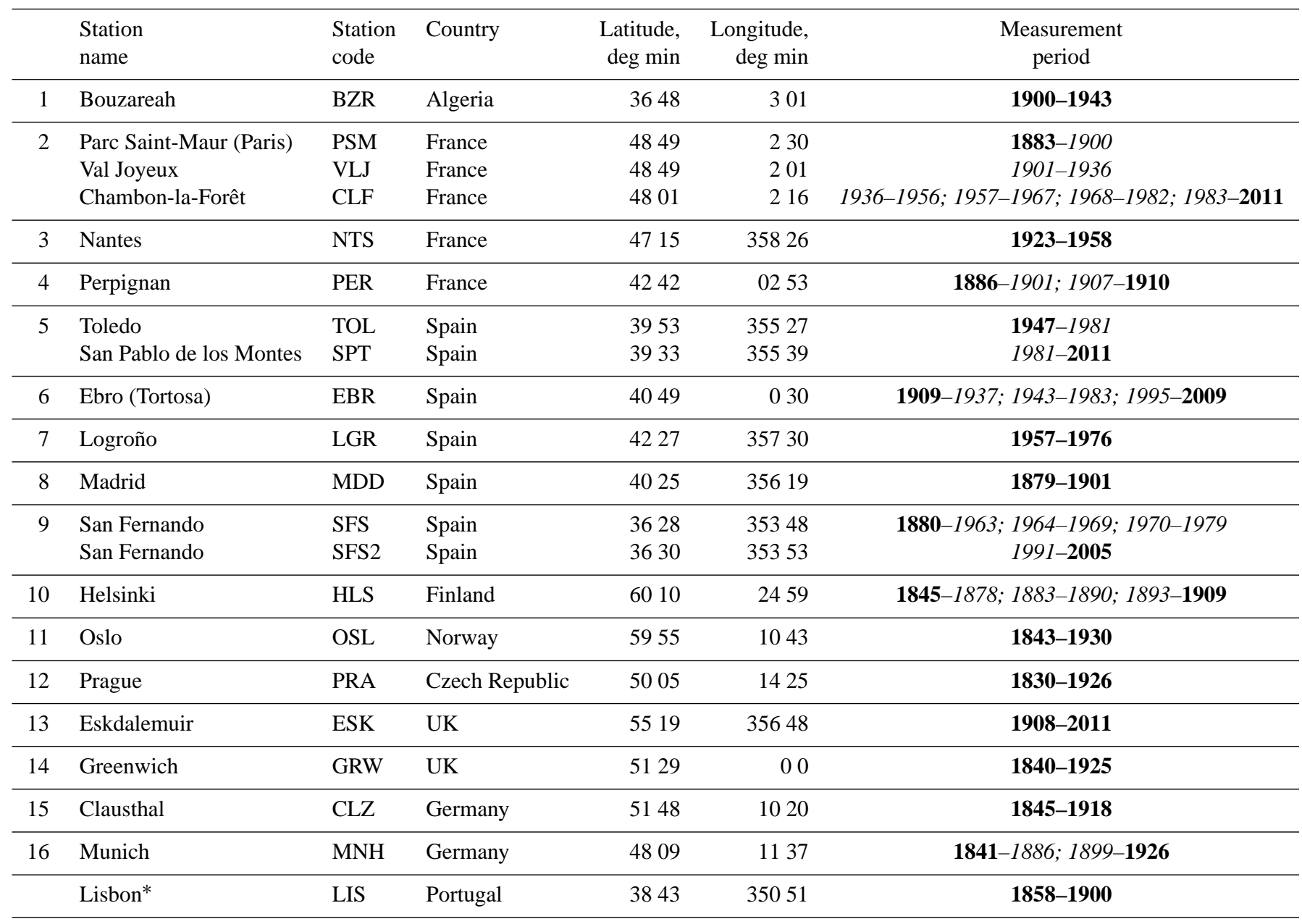

* LIS station was not used as a reference series for HTs, only for VA.

dates (marked by grey vertical lines) correspond to changes in instruments, measuring and calculating routines, station re-location, etc. mentioned in the station logbooks and annual books (Table 3).

\subsection{Homogeneity breaks}

The relative HTs were applied to differences between the y $2 \mathrm{y} \mathrm{d} D / \mathrm{d} t$ for COI and the first derivatives of $\mathrm{RS}^{\text {obs }}-D$, $\mathrm{RS}^{\mathrm{w}} \mathrm{COI}_{-} D$ and $\mathrm{RS}^{\mathrm{w} / \mathrm{oCO}}-D$. The results are shown in Fig. 11 (thin lines). As expected, the greatest contribution to the inhomogeneity level is given by the two noisy periods at the end of the 19th century and by the mid-20th century. As was mentioned above, we decided to correct only the homogeneity breaks that occurred after 1951, since we have no precise information from metadata to compute the proper corrections for earlier period. Therefore, we calculated the HT statistics for the period from 1951 to 2012 exclusively (Fig. 11).
As one can see, the HTs show a number of possible breaks. Some of them are seen only in HT statistics, but others coincide with known dates of instrument changes (Table 3). All of them are shown in Fig. 11, with grey vertical lines.

\subsection{Correction of the breaks from 1951 to 2012}

The visual analysis applied to the $D$ and $\mathrm{d} D / \mathrm{d} t$ COI series directly and to series of differences between those and reference series, as well as results of HTs, allowed us to select 11 possible homogeneity breaks during the period from 1951 to 2012. They are listed in Table 3, together with the metadata found for this period. Table 3 also shows HBs and metadata for the period from June 1874 to January 1951, to which we chose not to apply corrections as explained above. Only four of the HBs the period from 1951 to 2012 were chosen for correction: breaks \#1, \#4, \#5 and \#11. These breaks (1) are clearly seen in both $D$ and $\mathrm{d} D / \mathrm{d} t$ data series, (2) are detected by the HTs, (3) the metadata provide clear artificial sources for these breaks, and (4) unambiguous correction values can 


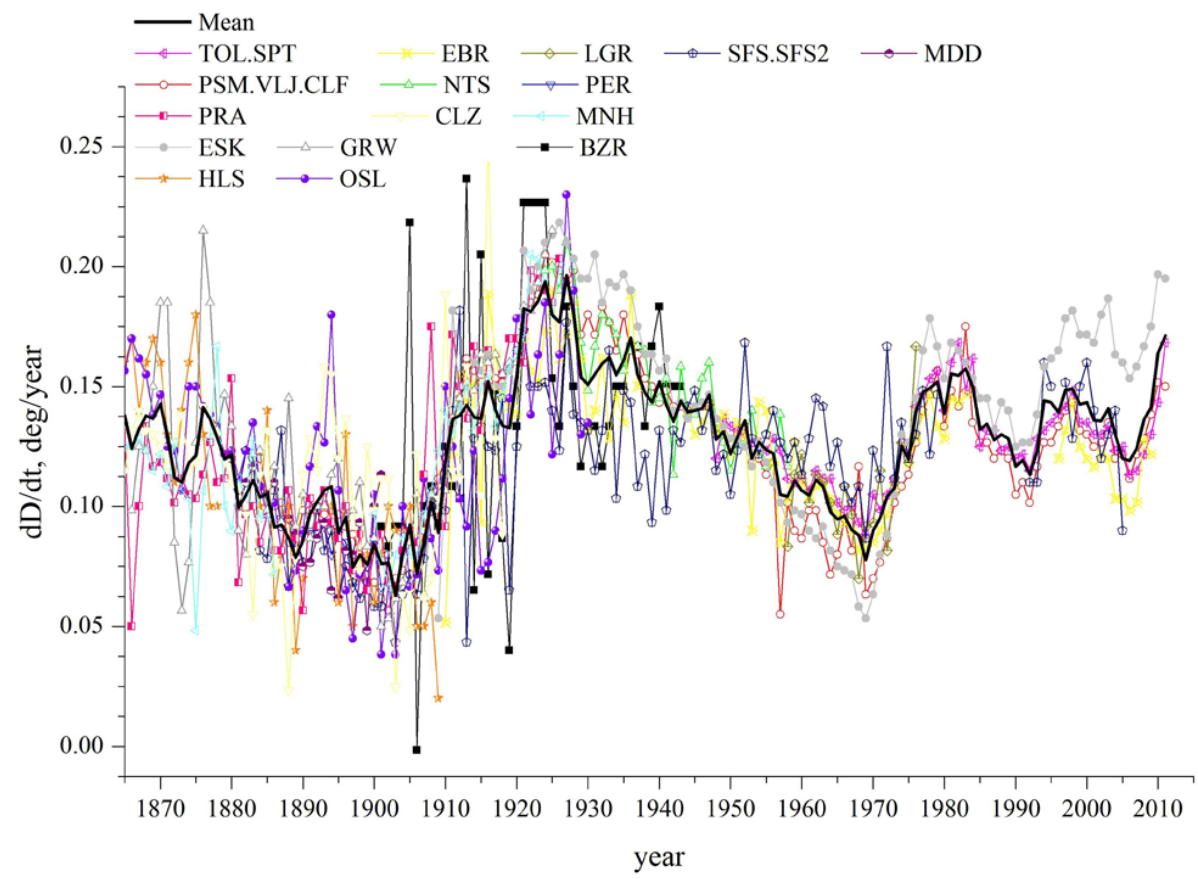

Fig. 9. First derivatives (SV) of 16 reference series from different stations (lines with dots of different form and colour) and their mean $\mathrm{RS}^{\mathrm{obs}}-D$.

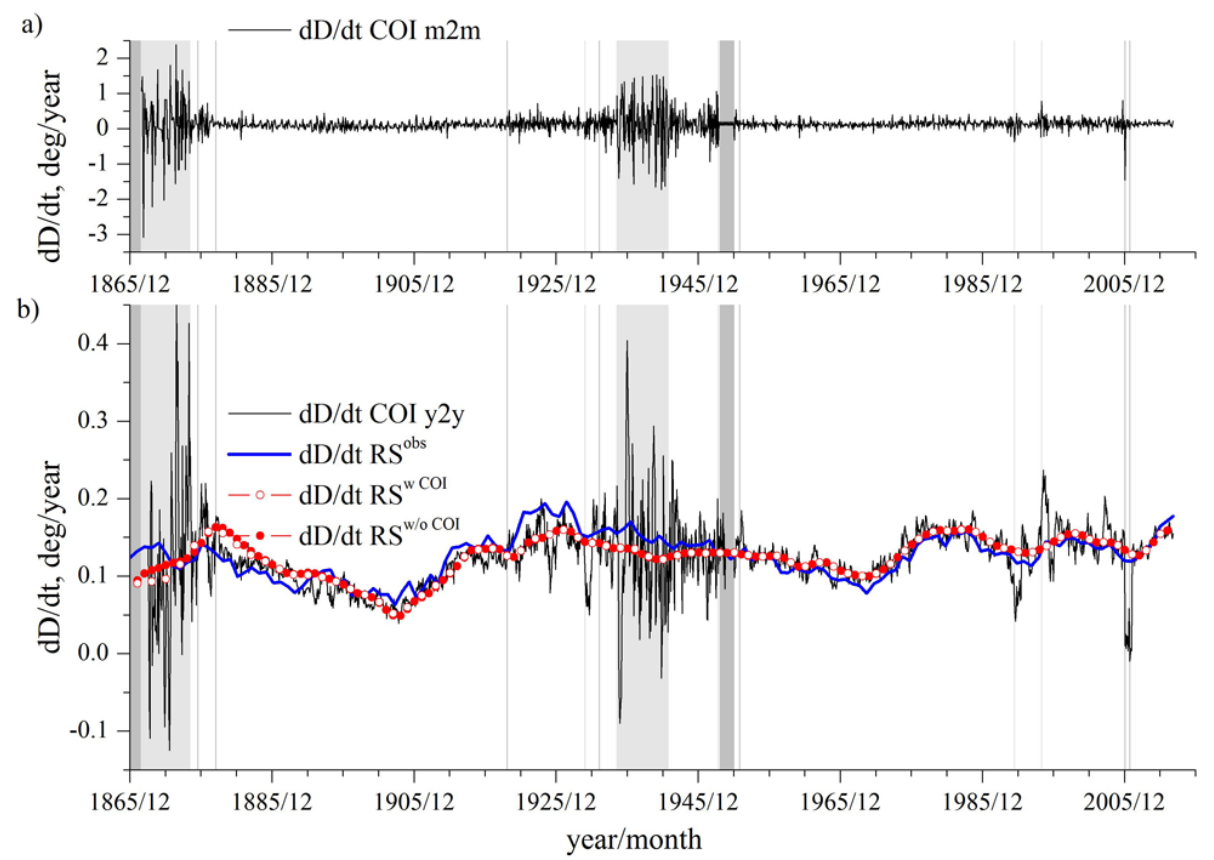

Fig. 10. (a) Month-to-month derivative $(\mathrm{m} 2 \mathrm{~m} \mathrm{~d} D / \mathrm{d} t$ ) of COI $D$ series. (b) Year-to-year derivative (y2y $\mathrm{d} D / \mathrm{d} t)$ of COI $D$ series (thin black line) together with first derivatives of $\mathrm{RS}^{\text {obs }}-D$ (thick blue line), $\mathrm{RS}^{\mathrm{W}} \mathrm{COI}_{-} \mathrm{D}$ and $\mathrm{RS}^{\mathrm{w} / \mathrm{o}} \mathrm{COI}_{-} D$ (red line with open and filled circles, respectively). Vertical lines mark periods of possible homogeneity breaks for COI data (see Table 3).

be calculated to correct the breaks. For the remaining possible breaks, one or two of these conditions are not fulfilled. Figure 12 shows the original and corrected series of $D$ and $\mathrm{d} D / \mathrm{d} t$ for the period 1951-2012. The whole corrected $D$ series and its $\mathrm{y} 2 \mathrm{y} \mathrm{d} D / \mathrm{d} t$ are shown in Fig. 8 to be compared with the original ones. The correction values for $D$ are given in Table 3. 

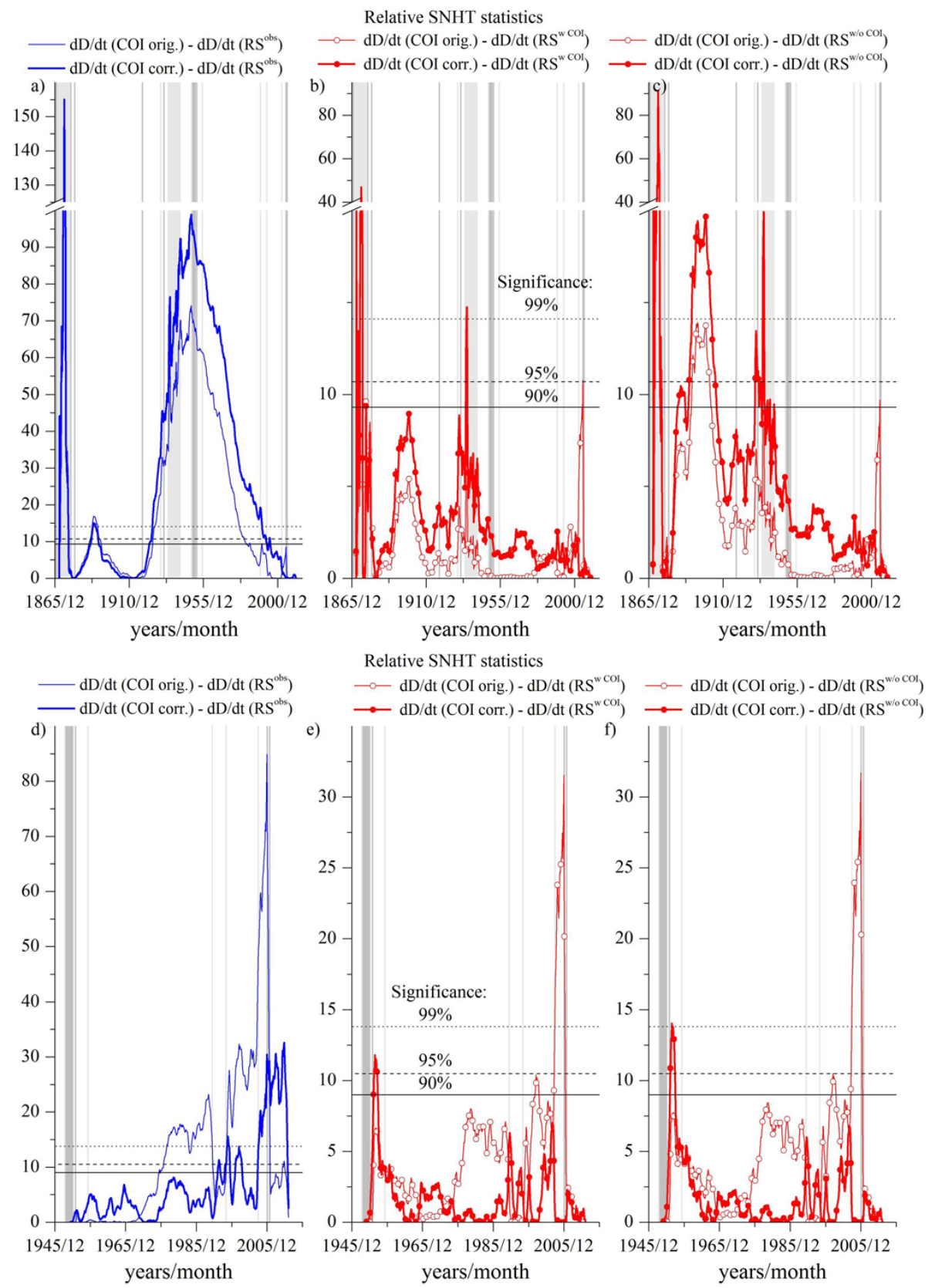

Fig. 11. (a-c) SNHT statistics for series of differences between first derivatives of COI $(\mathrm{y} 2 \mathrm{y} \mathrm{d} D / \mathrm{d} t)$ and reference series $\left(\mathrm{RS}^{\text {obs }}-D-\right.$ left panel, $\mathrm{RS}^{\mathrm{w}}$ COI $-D$ and $\mathrm{RS}^{\mathrm{w} / \mathrm{o}} \mathrm{CO}_{-} D-$ middle and right panels, respectively). (d-f) Same but for the period from 1951 to 2012 . Significance levels are shown by horizontal lines. Results for original series are shown by thin lines, and results for corrected series are shown by thick lines. Vertical lines mark periods of possible homogeneity breaks for COI data (see Table 3).

Focusing now on the corrected breaks, we see that break \#1 (December 2005-January 2006) arises from the installation of a new instrument in June 2006 and the introduction of a related correction in January 2006. It is clearly seen as an outlier in $\mathrm{m} 2 \mathrm{~m} \mathrm{~d} D / \mathrm{d} t$ series and as a period of shifted values in the $\mathrm{y} 2 \mathrm{y} \mathrm{d} D / \mathrm{d} t$ series. The difference between the measurements obtained with old and new devices was calculated in 2006 and is equal to 6 arcmin. Previously, this correction was applied only between January and June 2006. We here applied the correction from January 2006 backward in time.

Break \#4 (April 1994) coincides with a change of the magnet suspension wire which was broken. The $\mathrm{m} 2 \mathrm{~m} \mathrm{~d} D / \mathrm{d} t$ value for this month was substituted for the mean value for the next four months, and the whole $D$ series was recalculated from the new $\mathrm{d} D / \mathrm{d} t$ series. 

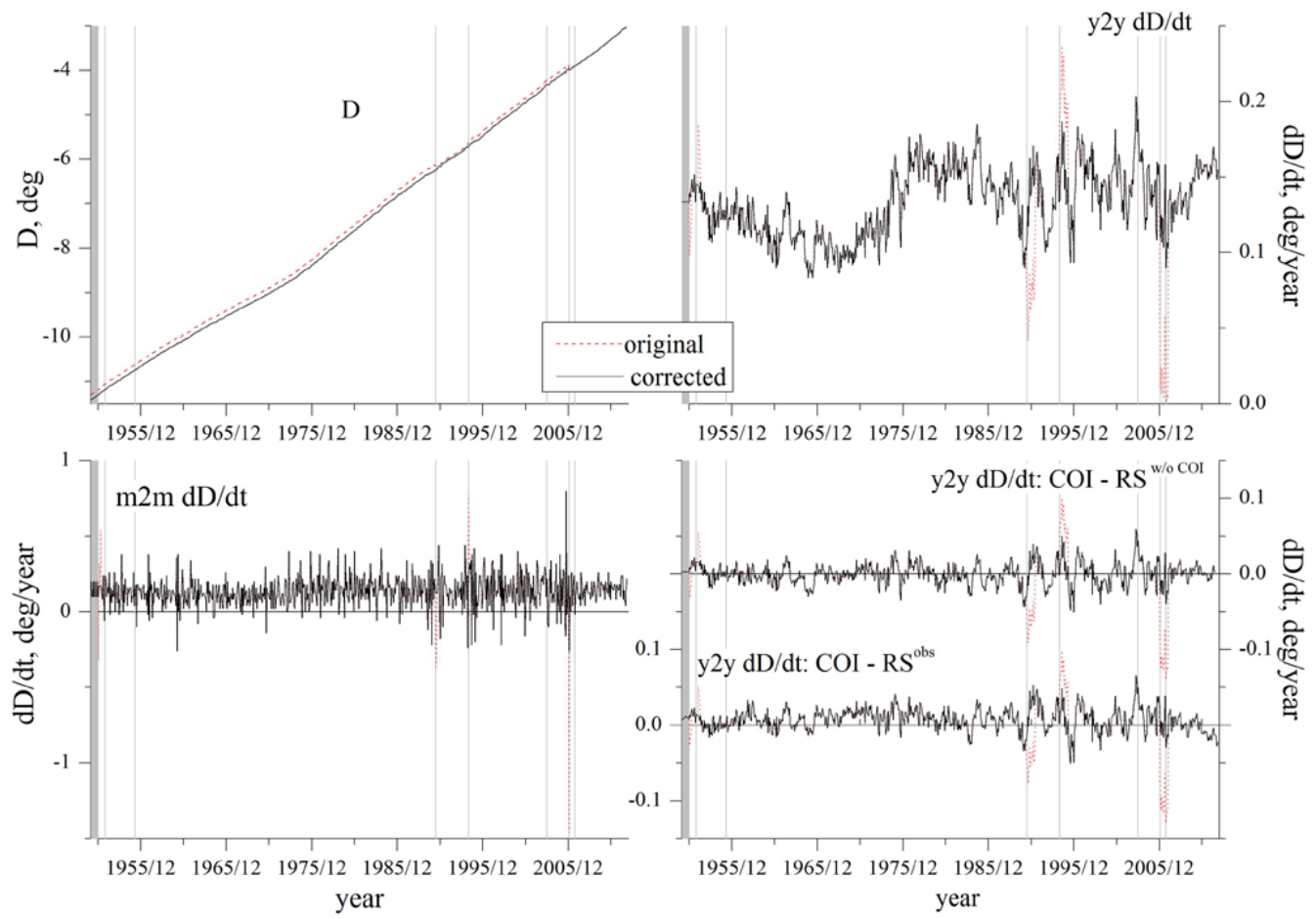

Fig. 12. Original (red dashed lines) and corrected (black solid lines) series of $D$ (top left panel), first derivatives (m2m $\mathrm{d} D / \mathrm{d} t-\mathrm{bottom}$ left panel; y $2 \mathrm{y} \mathrm{d} D / \mathrm{d} t$ - top right panel) and differences between first derivatives of COI series and reference series (bottom right panel) from 1951 to 2012. Breaks (see Table 3) are marked by vertical lines.

Break \#5 (June 1990-July 1990) is probably associated with a number of perturbations caused by building construction in the nearby area. The break was corrected with substitution of the $\mathrm{m} 2 \mathrm{~m} \mathrm{~d} D / \mathrm{d} t$ values for these points by the mean values computed from preceding and following periods of 80 months, and the whole $D$ series was re-calculated from the new $\mathrm{d} D / \mathrm{d} t$ series.

Break \#11 (January 1951-March 1951) arises due to important methodological changes in the observation procedures and the end of the period of interpolated data from October 1948 to December 1950. This break was corrected by linear interpolation of the $D$ series between those two epochs.

As was mentioned before, the HBs found for the period from July 1867 to December 1950 (see Fig. 8) were left uncorrected since the quality of the data does not allow us to calculate reasonable correction values. However, some comments have to be made about the quality of the data for this period. The period of interpolated data (January 1949December 1950) is clearly seen in the $\mathrm{m} 2 \mathrm{~m} \mathrm{~d} D / \mathrm{d} t$ variations as a period of very regular $\mathrm{d} D / \mathrm{d} t$ variations. It was preceded by a period of low-quality measurements (October 1937October 1941) with highly variable $\mathrm{m} 2 \mathrm{~m}$ and $\mathrm{y} 2 \mathrm{y}$ derivatives. The period from 1875 to 1937 contains data of fair quality but with a number of possible breaks listed in Table 3 . The data before 1875 are of low quality due to irregularity of the measurements and inaccurate local azimuth determination. This can be concluded from Fig. 13, which shows COI $D$ series (monthly, both original and corrected, and annual calculated from corrected monthly data) alongside annual $D$ series from Lisbon Observatory (LIS, see Table 4). The LIS and COI stations were located $\sim 200 \mathrm{~km}$ from each other; as a result, the two series of $D$ are expected to be very similar. Nevertheless, early COI $D$ data show clearly different trend compared to LIS $D$ series during the period from July 1867 to about August 1871. COI $D$ data for this period have to be marked as unreliable for any model based on historical geomagnetic measurements.

The differences between the corrected COI $\mathrm{d} D / \mathrm{d} t$ series and RSs were subjected to statistical HTs, similar to the original ones. The results are presented in Fig. 11 as thick lines. Figure 11 shows the HT statistics for the time period when corrections were applied. In this figure, differences between corrected COI $\mathrm{d} D / \mathrm{d} t$ and $\mathrm{RS}^{\text {obs }}-D$ (left panel) still show highly significant homogeneity breaks around 19911999 and 2003-2007. For the rest of the time period, there are no breaks with significance greater than $90 \%$. The HTs of the corrected COI $\mathrm{d} D / \mathrm{d} t$ differences to $\mathrm{RS}^{\mathrm{w} / \mathrm{o}} \mathrm{COI}_{-} D$ and $\mathrm{RS}^{\mathrm{w}} \mathrm{CO}-D$ (Fig. 11, middle and right panels) are very similar to each other and show only one break around 19511952, which is nevertheless significant at more than $95 \%$. This is an indication that the estimations for COI site from 


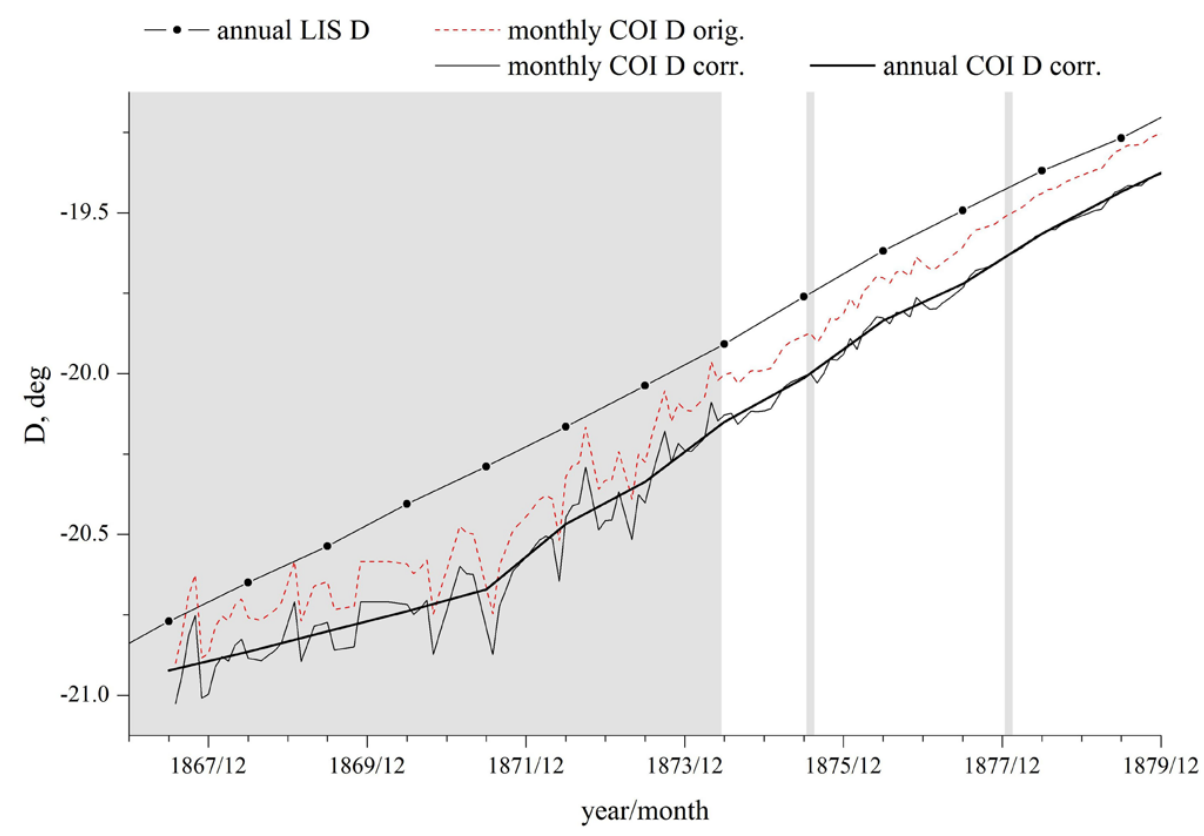

Fig. 13. Comparison of COI $D$ (monthly and annual) and annual LIS $D$ series for the early measurement period. Vertical lines mark epochs of changes in the instruments and initial period of unreliable data for COI $D$.

"COV-OBS w/o COI" model are rather well constrained by all the other European observatories. When including local data, the resulting "COV-OBS w COI" gives similar estimates and, accordingly, similar HT statistics. In this context, valid for regions very densely sampled as is the case of modern Europe, geomagnetic field models are only weakly sensitive to the HBs that may have occurred in one station. As a result, they can be used to produce reference series and are efficient in identifying HBs in that particular station. It can be argued from analysis of Fig. 11 that $\mathrm{RS}^{\mathrm{w} / \mathrm{o}} \mathrm{COI}_{-} D$ and $\mathrm{RS}^{\mathrm{w}} \mathrm{COI}_{-} D$ are not able to detect the HBs around 19911999 and 2003-2007, which are detected by $\mathrm{RS}^{\mathrm{obs}}-D$. We think this is an indication that those HBs are related to peaks of global geomagnetic activity, as we already noticed for the $\mathrm{Ki}$ series. An external component is in fact expected to be present in geomagnetic raw data from observatories, but not in the predicted series from internal geomagnetic field models. It also has to be noted that models predict the variations of the geomagnetic components for the particular location, whereas the data from relatively close African and European observatories can give only the expected mean variations of the studied parameters over a quite big region.

For the period prior to the International Geophysical Year (IGY) in 1957-1958 (see e.g. Olsen et al., 2010, Fig. 4), represented in Fig. 11 and beginning of curves in Fig. 11, the situation is quite different. The number of observatories being much lower before IGY, the degree of response of geomagnetic field models to data from a single station is higher, and for the case in study it means that the two models "COVOBS w/o COI" and "COV-OBS w COI" predict significantly different series for COI. Accordingly, the HT statistics for the two geomagnetic field models are clearly different, as shown in Fig. 11 (middle and right panels). The effect of correcting the four breaks \#1, \#4, \#5 and \#11 in the more recent period is now to enhance the HBs in the older period, which were left uncorrected (thicker curves with higher peak amplitudes than thinner curves). Unfortunately, we cannot use confidently neither $\mathrm{RS}^{\mathrm{w}} \mathrm{COI}-D$ (which is "contaminated" by COI HBs) nor $\mathrm{RS}^{\text {w/o }} \mathrm{COI}_{-} D$ to help identify possible old HBs, since as we see in Fig. 11 some produced peaks appear at periods of regular running of the observatory, as far as we know (e.g. around 1895). It is probably safer to get confirmation of old HBs from reference series RS ${ }^{\text {obs }}-D$ (Fig. 11, left panel), although as already discussed we then encounter the difficulty of separating peaks due to geomagnetic activity cycles.

The analysis of the changes in CRMSE values confirms the increase of the homogeneity of the corrected series. Figure 14 shows CRMSE of corrected COI $\mathrm{d} D / \mathrm{d} t$ monthly series (using $\mathrm{RS}^{\text {obs }}-D, \mathrm{RS}^{\mathrm{w}} \mathrm{COI}_{-} D$ and $\mathrm{RS}^{\mathrm{w} / \mathrm{o}} \mathrm{COI}_{-} D$ as reference series) plotted versus corresponding values of the original series. As one can see, the CRMSEs of the corrected series are lower than those for the original data, for all RSs, meaning that the corrected series is more homogeneous.

\subsection{New information provided by the homogenized series}

We used the homogenized $D$ series to improve the description of the geomagnetic jerks as seen in COI during the last $\sim 150 \mathrm{yr}$. Geomagnetic jerks are defined as V-like changes in 


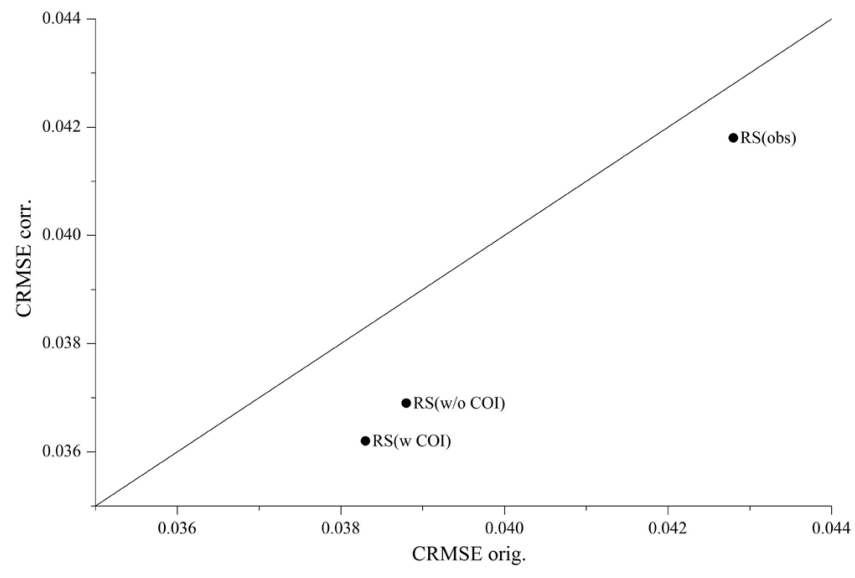

Fig. 14. CRMSE of corrected vs. original $\mathrm{d} D / \mathrm{d} t$ COI series.

the secular variation trend or step-like changes in the secular acceleration and occur in a time period of a few months (e.g. Courtillot et al., 1978). They are more easily seen in the eastward component $(Y)$ time series of magnetic observatories and, for small declination values as in COI, also in the declination time series. These are, in principle, the geomagnetic field components least affected by the external fields. According to previous work, seven global jerks have been detected in observatories all over the world during the 18672012 period: in 1901, 1913, 1925, 1969 and 1978 (Alexandrescu et al., 1996), in 1991 (Macmillan, 1996) and in 1999 (Mandea et al., 2000). The detection is not without ambiguity: some time shift has been reported for the 1969 and 1978 events, which could have been seen later at 1972 and 1982, respectively, in the Southern Hemisphere observatories (Alexandrescu et al., 1996); other features seem to be seen only in the observatories of localized regions, as in 1932 and 1949 for the Pacific and America areas (Alexandrescu et al., 1996), in 1986 for South Africa and the South Pacific (De Michelis and Tozzi, 2005) and in 2003 in a limited area near the $90^{\circ} \mathrm{E}$ meridian (Olsen and Mandea, 2007). Chulliat et al. (2010) report a local jerk in Africa in 2007.

Figure 15 shows the SV of the original and corrected COI annual $D$ series. The 1901, 1913 and 1925 jerks are clearly seen in the original COI data. The noisy period between 1930 and 1950 does not allow confirmation of if the 1932 and the 1949 events could be or could not be seen in COI data. Then, the 1969 and 1978 jerks are again clearly identified in COI as already verified by Pais and Miranda (1995). As one can see, the breaks in the data homogeneity coincide with the periods of the jerk in 1991 and between the reported local jerks of 2003 and 2007, around 2005. There is also a HB between two jerks in 1991 and 1999. These inhomogeneities could complicate the detection of the jerks. We see the following differences after applying the homogeneity corrections to the declination data series: (1) the amplitude of the 1991 jerk, which was exaggerated in the original data due to superposition of environmental noise, is reduced to more reasonable values; (2) as a result of this correction, the following event can be more adequately localized at 1999 in agreement with other observatories; (3) finally, after homogenization, the 2007 event is also seen in COI. This is not in disagreement with Chulliat et al. (2010), where in their Fig. 2 they plot a positive value for $\Delta \ddot{Y}$ in 2007 over the Iberian Peninsula, though the maximum is centred southern, over the South Atlantic. On the other hand, we confirm that the 2003 jerk is not seen in COI declination data, in agreement with Fig. 9 of Olsen and Mandea (2007) where $\Delta \ddot{Y}$ is very small over the Iberian Peninsula. We believe that the homogenized data allow a more correct description of the recent jerks as seen in COI declination data.

\section{Conclusions}

We studied the homogeneity of two historical series of the geomagnetic parameters measured by the Coimbra Geomagnetic Observatory, Portugal, from 1867 to 2012 (declination) and from 1951 to 2012 (local geomagnetic K index). To this end, we present an extended report of the history of COI magnetic observatory, its instruments and routines. When applying the homogeneity tests, the Ki series was studied "as is", whereas the first time derivative of the $D$ series was used, instead of the raw $D$ series, to identify homogeneity breaks. The Coimbra series were compared to available reference series: local indices from other observatories and $\mathrm{Kp}$ in the case of $\mathrm{K}$ index, and measurements from other observatories and data estimated from geomagnetic field models in the case of $D$. A number of artificial homogeneity breaks related to instrumental changes and station relocation were detected using both visual analysis and statistical homogeneity tests. Some of these breaks were corrected depending on the available metadata and on the quality of the data themselves.

The corrected series show more consistency with the data from other geomagnetic observatories. The corrected $\mathrm{Ki}$ and $D$ series were also used to analyse the character of the geomagnetic field variations during the second half of the 20th century. In particular, the analysis of the corrected Ki series confirms the increase of the geomagnetic activity from the middle to the end of the 20th century and the latitudinal dependence of this increase. As for the corrected $D$ series, the analysis of its first derivatives shows that the 1991 and 1999 jerks are seen in Coimbra, as in other observatories based on which the conclusion of globality for these jerks has been previously drawn. This analysis also shows that although the 2003 jerk is not seen in COI, because it is centred on the meridian $90^{\circ} \mathrm{E}$, the 2007 jerk can be seen in the $D$ component. The analysis of the corrected $D$ series further suggests that this last jerk is seen in COI a little earlier, in 2006. 


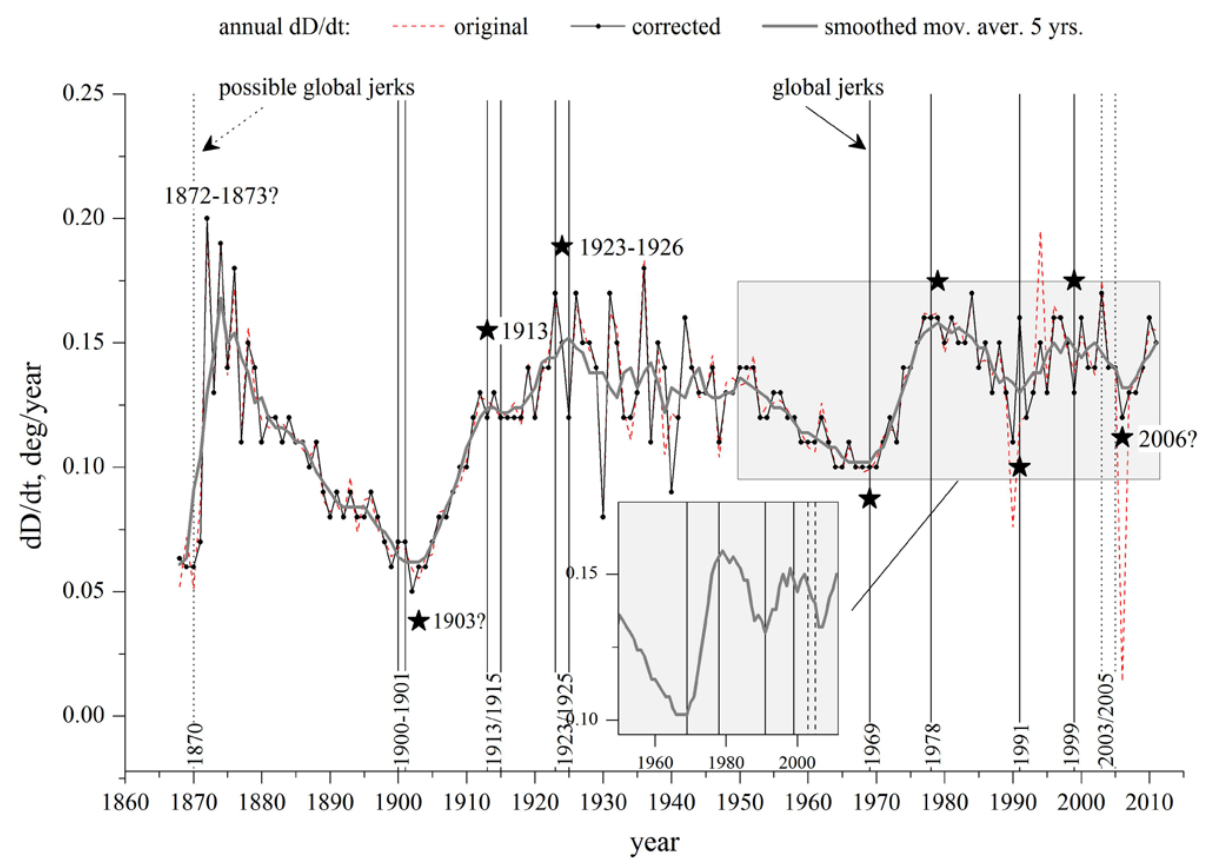

Fig. 15. Secular variation of COI $D$ : original data - red dashed line, corrected - black line with dots, smoothed by 5 yr moving averaging grey thick line. Vertical lines show dates of global jerks (solid) and possible global jerks (dotted). Stars identify jerks seen in COI $D$ data. Grey rectangles single out the period of corrected data.

The present study shows examples of the use of statistical homogeneity tests to study time series that show natural quasi-cyclic variations and long-term trends, uncommon to meteorological series to which these tests have been largely applied. We solved these difficulties by applying relative homogeneity tests to series from neighbouring magnetic stations using the closest Spanish stations, in the former case, and by applying homogeneity tests to first derivatives of time series in the latter case.

This study also draws attention to the importance of correcting HBs in geomagnetic field series from observatories in order to produce good-quality geomagnetic models, on the one hand, as well as to the importance of having goodquality geomagnetic models to help identify HBs in observatory series, on the other hand. In regions densely sampled as is the case of Europe since the IGY, geomagnetic field models seem to be efficient in identifying HBs in one particular station. However, they lose this ability if strongly "contaminated" by the HBs themselves. A common effort could be planned between the most ancient magnetic observatories in order to collect old metadata and implement corrections of homogeneity breaks in the old series.

Acknowledgements. A. Morozova is supported by a postdoc FCT scholarship (SFRH/BPD/74812/2010). A. Pais is supported by FCT (PTDC/CTE-GIX/119967/2010) through the project COMPETE (FCOMP-01-0124-FEDER-019978). A. Morozova wishes to thank Masatoshi Yamauchi from Kiruna Observatory for kindly providing the metadata for KIR K index series. P. Ribeiro wishes to thank his colleagues from Toledo and Ebro observatories for kindly providing data and metadata for these two observatories. A. Pais wishes to thank Nicolas Gillet for kindly computing the COV-OBS w/o COI model to use in this study. The authors would also like to thank two anonymous reviewers for their helpful comments and suggestions.

Topical Editor L. Blomberg thanks M. Mandea and one anonymous referee for their help in evaluating this paper.

\section{References}

Alexandersson, H. and Moberg, A.: Homogenization of swedish temperature data. Part I: Homogeneity test for linear trends, Int. J. Climatol., 17, 25-34, 1997.

Alexandrescu, M., Gibert, D., Hulot, G., LeMouël, J.-L., and Saracco, G.: Worldwide wavelet analysis of geomagnetic jerks, J. Geophys. Res., 101, 21975-21994, 1996.

Beggan, C. and Whaler, K.: Forecasting secular variation using core flows, Earth Planet. Space, 62, 821-828, 2010.

Buishand, T.: Some methods for testing the homogeneity of rainfall records, J. Hydrol., 58, 11-27, 1982.

Chulliat, A., Thébault, E., and Hulot, G.: Core field acceleration pulse as a common cause of the 2003 and 2007 geomagnetic jerks, Geophys. Res. Lett., 37, L07301, doi:10.1029/2009GL042019, 2010.

Costa, A. C. and Soares, A.: Homogenization of climate data: review and new perspectives using geostatistics, Math. Geosci., 41, 291-305, 2009.

Courtillot, V., Ducruix, J., and LeMouël, J.-L.: Sur une accélération récente de la variation séculaire du champ géomagnétique terrestre, CR Acad. Sci. Paris. Ser. D, 287, 1095-1098, 1978. 
Custódio de Morais, J.: Advertência, in Observações Meteorológicas, Magnéticas e Sismológicas feitas no Instituto Geofísico (2 Parte - Magnetismo Terrestre), Vol. 81-87, Tipografia Atlântida, Coimbra, Portugal, 16 pp., 1952.

De Michelis, P. and Tozzi, R.: A local intermittency measure (LIM) approach to the detection of geomagnetic jerks, Earth Planet. Sci. Lett., 235, 261-272, 2005.

Du, Z. L.: The correlation between solar and geomagnetic activity - Part 1: Two-term decomposition of geomagnetic activity, Ann. Geophys., 29, 1331-1340, doi:10.5194/angeo-29-13312011, 2011.

Ferraz de Carvalho, A.: O Magnetismo Terrestre em Coimbra: Resumo das observações de 53 anos (1866-1918), Imprensa Académica, Coimbra, Portugal, 46 pp., 1920.

Gillet, N., Jault, D., Finlay, C. C., and Olsen, N.: Stochastic modeling of the Earth's magnetic field: Inversion for covariances over the observatory era, Geochem. Geophys. Geosyst., 14, 766-786, 2013.

Jackson, A. and Finlay, C. C.: Geomagnetic secular variation and its applications to the core, Treatise on geophysics, 5, 147-193, 2007.

Khaliq, M. N. and Ouarda, T. B. M. J.: On the critical values of the standard normal homogeneity test (SNHT), Int. J. Climatol., 27, 681-687, 2007.

Korte, M., Mandea, M., and Matzka, J.: A historical declination curve for Munich from different data sources, Phys. Earth Planet. In., 177, 161-172, 2009.

Love, J. J.: Secular trends in storm-level geomagnetic activity, Ann. Geophys., 29, 251-262, doi:10.5194/angeo-29-251-2011, 2011.

Love, J. J., Rigler, E. J., and Gibson S. E.: Geomagnetic detection of the sectorial solar magnetic field and the historical peculiarity of minimum 23-24, Geophys. Res. Lett., 39, L04102, doi:10.1029/2011GL050702, 2012.

Macmillan, S.: A geomagnetic jerk for the early 1990's, Earth Planet. Sci. Lett., 137, 189-192, 1996.

Mandea, M., Bellanger, E., and LeMouël, J.-L.: A geomagnetic jerk for the end of the 20th century?, Earth Planet. Sci. Lett., 183, 369-373, 2000.

Mandea, M., Holme, R., Pais, A., Pinheiro, K., Jackson, A., and Verbanac, G.: Geomagnetic jerks: rapid core field variations and core dynamics, Space Sci. Rev., 155, 147-175, 2010.

Martini, D. and Mursula, K.: Centennial geomagnetic activity studied by a new, reliable long-term index, J. Atmos. Sol.-Terr. Phys., 70, 1074-1087, 2008.

Maus, S., Silva, L., and Hulot, G.: Can core-surface flow models be used to improve the forecast of the Earths's main magnetic field?, J. Geophys. Res., 113, B08102, doi:10.1029/2007JB005199, 2008.

Menvielle, M., Iyemori, T., Marchaudon, A., and Nosé, M.: Geomagnetic Indices, in: Geomagnetic Observations and Models (Vol. 5), edited by: Mandea, M. and Korte, M., Springer Science+ Business Media, 183-228, 2011.
Menvielle, M., Papistashvili, N., Hakkinen, L., and Suckdorff, C. Computer production of $\mathrm{K}$ indices: review and comparison of methods, Geophys. J. Int., 123, 866-886, 1995.

Minamoto, Y. and Taguchi, Y.: Significant decreases in the geomagnetic indices in the ascending phase of Solar Cycle 24, Earth Planet. Space, 61, e25-e28, 2009.

Morozova, A. L. and Valente, M. A.: Homogenization of Portuguese long-term temperature data series: Lisbon, Coimbra and Porto, Earth Syst. Sci. Data, 4, 187-213, doi:10.5194/essd-4187-2012, 2012.

Morozova, A. L., Pribeiro, P., Valente, M. A., and Pais, M. A.: On homogenization of Portuguese meteorological and geophysical data series, Proceedings of 7th Spanish-Portuguese Assembly of Geodesy and Geophysics (7AHPGG), 25-29/06/2012, San Sebatian, Spain, edited by: Zurutuza, J., 293-296, 2012.

Olsen, N. and Mandea, M.: Investigation of a secular variation impulse using satellite data: The 2003 geomagnetic jerk, Earth Planet. Sci. Lett., 255, 94-105, 2007.

Olsen, N., Hulot, G., and Sabaka, T. J.: Sources of the geomagnetic field and the modern data that enable their investigation, in: The Handbook of Geomathematics, edited by: Freeden, W., Nashed, Z., and Sonar, T., Springer, Heidelberg, 105-124, 2010.

Pais, M. A. and Miranda, J. M. A.: Secular variation in Coimbra (Portugal) since 1866, J. Geomag. Geoelectr., 47, 267-282, 1995.

Seiça e Santos, V. G. de: Instituto Geofísico da Universidade de Coimbra (Bosquejo Histórico), Unpublished manuscript, Coimbra, 391 pp., available at: http://bdigital.sib.uc.pt/hc/ UCSIB-1-5-5-12/UCSIB-1-5-5-12_item2/index.html, 1995.

Svalgaard, L. and Cliver, E. W.: Heliospheric magnetic field 1835-2009, J. Geophys. Res., 115, A09111, doi:10.1029/2009JA015069, 2010.

Taylor, K. E.: Summarizing multiple aspects of model performance in a single diagram, J. Geophys. Res., 106, 7183-7192, 2001.

Venema, V. K. C., Mestre, O., Aguilar, E., Auer, I., Guijarro, J. A., Domonkos, P., Vertacnik, G., Szentimrey, T., Stepanek, P., Zahradnicek, P., Viarre, J., Müller-Westermeier, G., Lakatos, M., Williams, C. N., Menne, M. J., Lindau, R., Rasol, D., Rustemeier, E., Kolokythas, K., Marinova, T., Andresen, L., Acquaotta, F., Fratianni, S., Cheval, S., Klancar, M., Brunetti, M., Gruber, C., Prohom Duran, M., Likso, T., Esteban, P., and Brandsma, T.: Benchmarking homogenization algorithms for monthly data, Clim. Past, 8, 89-115, doi:10.5194/cp-8-89-2012, 2012.

Vokhmyanin, M. V. and Ponyavin, D. I.: Sector structure of the interplanetary magnetic field in the 19th century, Geophys. Res. Lett., 40, 3512-3516, doi:10.1002/grl.50749, 2013.

Zhang, Y., Sun, W., Feng, X. S., Deehr, C. S., Fry, C. D., and Dryer, M.: Statistical analysis of corotating interaction regions and their geoeffectiveness during solar cycle 23, J. Geophys. Res. Space Phys., 113, A8, A08106, doi:10.1029/2008JA013095, 2008. 